UMETNOSTNOZGODOVINSKI INŠTITUT FRANCETA STELETA ZRC SAZU

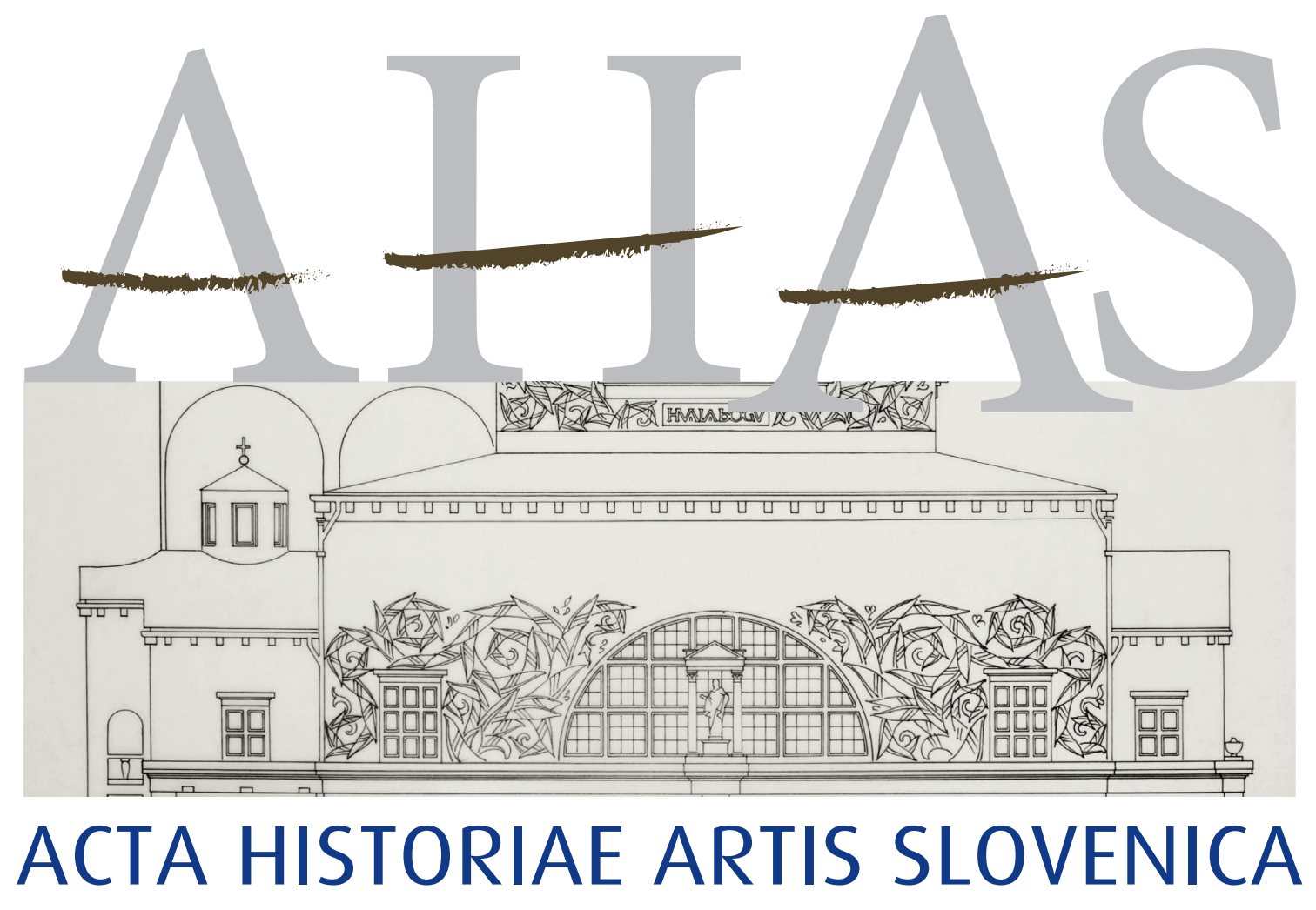

$26 \mid 1 \cdot 2021$ 
Umetnostnozgodovinski inštitut Franceta Steleta ZRC SAZU

France Stele Institute of Art History ZRC SAZU

\section{ACTA HISTORIAE ARTIS SLOVENICA \\ $26 \mid 1 \cdot 2021$}


Acta historiae artis Slovenica, 26/1, 2021

Znanstvena revija za umetnostno zgodovino / Scholarly Journal for Art History

ISSN 1408-0419 (tiskana izdaja / print edition) ISSN 2536-4200 (spletna izdaja / web edition)

Izdajatelj / Issued by

ZRC SAZU, Umetnostnozgodovinski inštitut Franceta Steleta / ZRC SAZU, France Stele Institute of Art History

Založnik / Publisher

Založba ZRC

Glavna urednica / Editor-in-chief

Katarina Mohar

Uredniški odbor / Editorial board

Renata Komić Marn, Tina Košak, Katarina Mohar, Mija Oter Gorenčič, Blaž Resman, Helena Seražin

Mednarodni svetovalni odbor / International advisory board

Günter Brucher (Salzburg), Ana María Fernández García (Oviedo), Hellmut Lorenz (Wien),

Milan Pelc (Zagreb), Sergio Tavano (Gorizia-Trieste), Barbara Wisch (New York)

Lektoriranje / Language editing

Oliver Currie, Manuela Dajnko, Andrea Leskovec, Tjaša Plut, Sergio Sozi

Prevodi / Translations

Ervin Köstler, Martina Malešič, Nika Vaupotič, Alessandro Quinzi, Samo Štefanac, Polona Vidmar

Celostni strokovni in jezikovni pregled / Expert and language editing

Blaž Resman

Oblikovna zasnova in prelom / Design and layout

Andrej Furlan

Naslov uredništva / Editorial office address

Acta historiae artis Slovenica

Novi trg 2, p. p. 306, SI -1001 Ljubljana, Slovenija

ahas@zrc-sazu.si; https://ojs.zrc-sazu.si/ahas

Revija je indeksirana $v$ / Journal is indexed in

Scopus, ERIH PLUS, EBSCO Publishing, IBZ, BHA

Letna naročnina / Annual subscription: $35 €$; Posamezna enojna številka / Single issue: $25 €$

Letna naročnina za študente in dijake: $25 €$

Letna naročnina za tujino in ustanove / Annual subscription outside Slovenia, institutions: $48 €$

Naročila sprejema / For orders contact

Založba ZRC

Novi trg 2, p. p. 306, SI-1001, Slovenija

E-pošta / E-mail: zalozba@zrc-sazu.si

AHAS izhaja s podporo Javne agencije za raziskovalno dejavnost Republike Slovenije.

AHAS is published with the support of the Slovenian Research Agency.

Tisk / Printed by Present d. 0. 0., Ljubljana

Naklada / Print run: 400

(c) 2021, avtorji in ZRC SAZU / 2021, Authors and ZRC SAZU

Besedilo tega dela je na voljo pod pogoji slovenske licence Creative Commons 4.0 CC BY NC ND, ki pa ne velja za slikovno gradivo. Za kakršnokoli nadaljnjo rabo slikovnega gradiva je treba pridobiti dovoljenje imetnika avtorskih pravic, navedenega v poglavju Viri ilustracij. Za avtorske pravice reprodukcij odgovarjajo avtorji objavljenih prispevkov. / The text of this publication is available under the conditions of the Slovenian licence Creative Commons 4.0 CC BY NC ND, which is not valid for the published images. Any further use of images requires permission from the copyright holder, stated in the section Photographic Credits. The copyrights for reproductions are the responsibility of the authors of published papers. 


\section{VSEBINA \\ Contents}

\section{DISSERTATIONES}

Janez Balažic

Fragmentarno ohranjene gotske stenske poslikave na zahodnem panonskem robu 7

Fragmentarily Preserved Gothic Murals on the Western Edge of Pannonia

\section{Mija Oter Gorenčič}

Die monastischen und kunsthistorischen Beziehungen zwischen Gaming und den

Kartausen im heutigen Slowenien unter besonderer Berücksichtigung der Memoria und der Herrschaftsrepräsentation der Habsburger und der Grafen von Cilli

Redovne in umetnostne povezave med Gamingom in kartuzijami v današnji Sloveniji

s posebnim ozirom na memorio in likovno reprezentacijo Habsburžanov in grofov Celjskih. 50

Samo Štefanac

Ponovno o koprski Pietà

Alessandro Quinzi

Rodbinske ambicije Sigismunda grofa Attems Petzenstein v luči umetnostnih naročil

Le ambizioni familiari del conte Sigismondo Attems Petzenstein alla luce

delle committenze artistiche

Polona Vidmar

Vorfahr oder König? Zur Rezeption der Porträts des 17. Jahrhunderts unter Franz Josef Fürst Dietrichstein (1767-1854)

Prednik ali kralj? Recepcija portretov iz 17. stoletja

$v$ času Franca Jožefa kneza Dietrichsteina (1767-1854)

Mateja Maučec

Vizualna propaganda Stadlerjevih ekumenskih prizadevanj v freskah Ivane Kobilce.

Visual Propaganda of Stadler's Ecumenic Project in Frescoes by Ivana Kobilca 
Vaidas Petrulis

Kaunas - a Baltic Garden City?

Kaunas - baltsko vrtno mesto?

Damjan Prelovšek

Plečnikovi načrti za cerkev sv. Križa v Zagrebu.

Plečnik's Plans for the Church of the Holy Cross in Zagreb

Martina Malešič

Risbe iz stockholmskih arhivov. Poskus rekonstrukcije švedske izkušnje

arhitektov Franceta in Marte Ivanšek

Drawings from the Stockholm Archives. An Attempt to Reconstruct

the Swedish Experience of Architects France and Marta Ivanšek.

183

\section{APPARATUS}

Izvlečki in ključne besede/Abstracts and Keywords

Sodelavci/Contributors

Viri ilustracij / Photographic Credits

195 
DISSERTATIONES

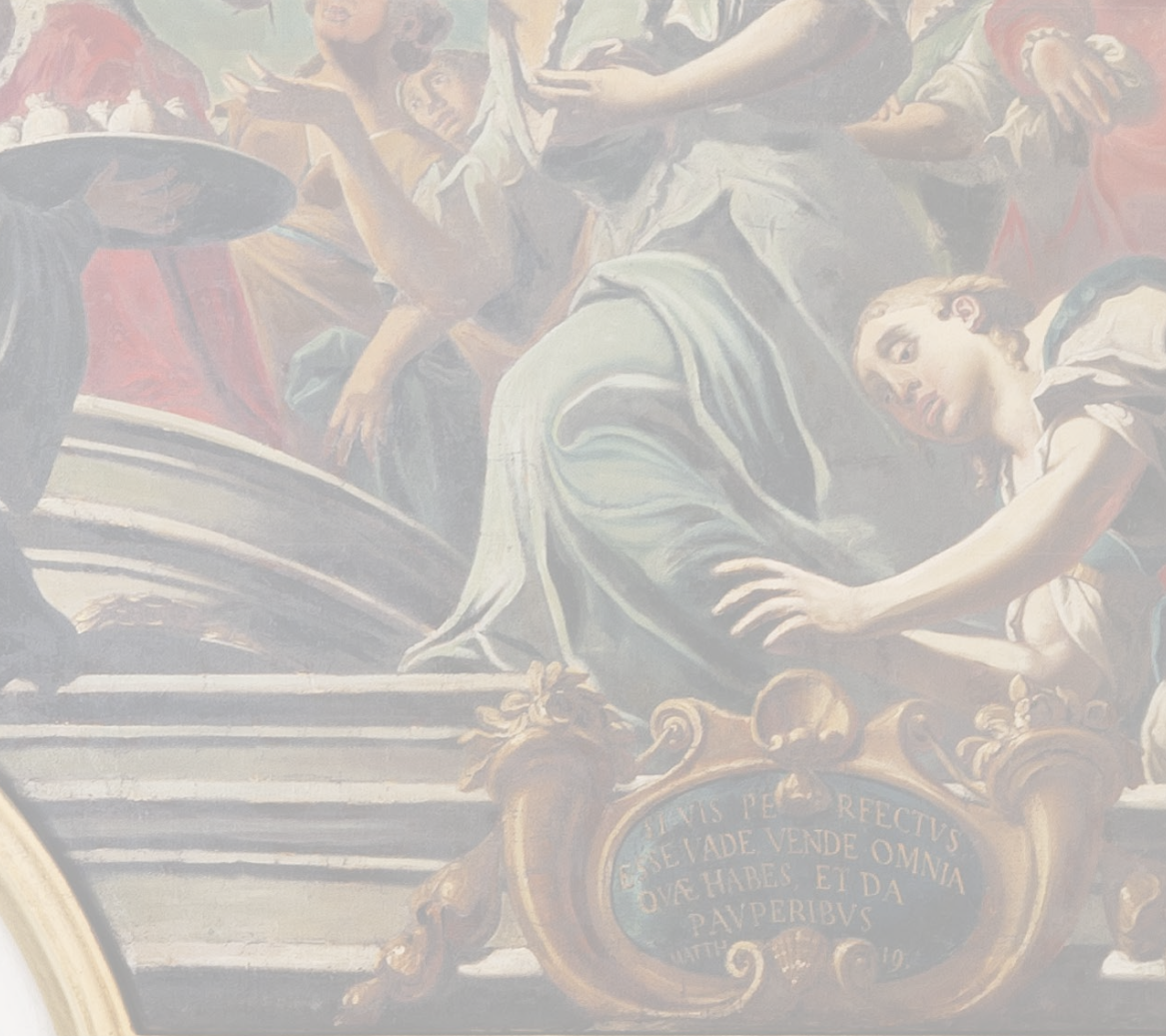




\title{
Risbe iz stockholmskih arhivov
}

\author{
Poskus rekonstrukcije švedske izkušnje arhitektov \\ Franceta in Marte Ivanšek
}

\section{Martina Malešič}

Kako dobro je bilo, da smo se ognili velikemu svetu arhitekture Nemčije, Francije in Amerike, saj nam ne bi mogla pomagati zaradi strašnih razlik v merilih. In kako prav je bilo, da smo se čutili bližji Švedski, Danski in Finski, ki so prvo delo, prebavo velikih vzorov že opravili in je bilo tisto, kar smo pri njih videli, že uporabno za nas. Skrbno napredno in vse še domačnostno se je vglavnem pokrivalo z našimi potrebami in navadami, deloma $z$ našimi možnostmi in našimi pričakovanji. ${ }^{1}$

S temi besedami je v svojem dnevniku arhitekt Edvard Ravnikar opisal specifično klimo arhitekturnega dogajanja na Slovenskem po 2. svetovni vojni, ki jo je močno zaznamovala naklonjenost skandinavskim oziroma nordijskim deželam. Slednje so tako v Evropi kot drugje po svetu prevzele vlogo pomembnega vzornika bolj humanističnega pristopa $\mathrm{h}$ gradnji stanovanj $\mathrm{z}$ dobro razvito stanovanjsko politiko in lepim, preprostim oblikovanjem vsakdanjega okolja. Tuje arhitekturne revije $^{2}$ so v petdesetih letih izdatno poročale o dosežkih skandinavske arhitekture in oblikovanja, ki so jih vestno spremljali tudi slovenski (in drugi jugoslovanski) arhitekti, poleg tega pa so - kot lahko sklepamo iz člankov in prevodov v arhitekturnih revijah - imeli dostop tudi do skandinavskih publikacij, vsaj do švedskih Byggmästaren in Form. O vsem, kar so prebrali v tujini, so pisali v sočasnem časopisju, sčasoma pa so se temu pridružila tudi poročila tistih, ki so na sever potovali sami. Številni so se v Skandinavijo podali zgolj turistično, mnogi pa tudi s ciljem, da bi v eni od nordijskih držav študirali, opravljali prakso ali pa se tam celo zaposlili. Slovenski arhitekti so množično potovali na sever, ${ }^{3}$ med njimi na primer France in Marta Ivanšek, Edvard Ravnikar, Ljubo Humek, Danilo Fürst, Mitja Jernejec, Nikolaj Bežek, Niko Kralj, Branka Tancig, Stanko Kristl,

1 Ravnikarjevi dnevniški zapisi so bili transkribirani in deloma objavljeni v: Nataša KOSELJ, Tradicija napredka. Kriteriji vrednotenja in metodologija zaščite arhitekture nastale med leti 1945-70 v Sloveniji, Ljubljana 2003 (tipkopis doktorske disertacije), str. 139.

2 Na primer švicarska Werk, italijanski Urbanistica in Casabella, pa tudi angleška Architectural Review in francoska Architecture d'aujourd'hui.

3 Tudi arhitekti drugih jugoslovanskih republik so bili dobro seznanjeni z arhitekturnim dogajanjem v skandinavskih državah, kar nam potrjujejo tako članki v revijah kot podatki o potovanjih posameznikov, vendar takšne pozornosti kot pri slovenski arhitekturni publiki drugje ne moremo zaslediti. O tem in o percepciji skandinavskih zgledov v širšem jugoslovanskem arhitekturnem kontekstu gl. Martina MALEŠIČ, Pomen skandinavskih vplivov za slovensko stanovanjsko kulturo, Ljubljana 2013 (tipkopis doktorske disertacije). 
Marija Vovk. ${ }^{4}$ Zgledovanje po skandinavskih, predvsem švedskih izkušnjah predstavlja pomembno poglavje $\mathrm{v}$ slovenski povojni arhitekturni zgodovini, na kar pogosto opozarjajo številne pregledne in monografske publikacije. ${ }^{5}$ Med tistimi, ki so odšli na Švedsko za dlje časa in je ta izkušnja v njihovem delu pustila zelo močen pečat, najpogosteje izpostavljajo prav arhitekta Ivanšek. France Ivanšek (1922-2007) in Marta Ivanšek, rojena Ravnikar (1920-2009), sta bila pomembna predstavnika slovenske povojne arhitekture. Po zaključku študija arhitekture na Tehniški fakulteti v Ljubljani, France kot diplomant pri profesorju Edvardu Ravnikarju in Marta kot diplomantka pri profesorju Jožetu Plečniku, sta leta 1954 odšla na Švedsko in tam ostala do leta 1959. Okrepljena s švedskimi izkušnjami sta izvedla več ključnih premikov, ki so bili v tem času za slovenski prostor napredni in edinstveni. Med njuna najpomembnejša dela štejemo stanovanjsko naselje Murgle v Ljubljani (1965-1986), kuhinjo SVEA (1960) ter domova za upokojence na Poljanah (1976) in v Trnovem (1981) v Ljubljani. Ustanovila sta močno obiskovani trgovini Interier v Ljubljani (1965) in Ambient v Mariboru (1970), ki sta slovenski trg obogatili z večjo in boljšo izbiro notranje opreme. Posebnega pomena, a pogosto ne dovolj poudarjen, pa je njun prispevek na področju stanovanjskega raziskovanja. Bila sta namreč prva, ki sta se sistematično ukvarjala tako z mnenjem uporabnikov kot s preučevanjem bivanjske ravni v slovenskih stanovanjih. ${ }^{6}$

Ivanška sta v slovenski arhitekturni zgodovini pogosto omenjena kot »ambasadorja «švedske kulture, ki sta iz Skandinavije v slovenski prostor prinesla vrsto za napredek stanovanjskega standarda ključnih modelov, na primer urbanistično idejo nizko-goste stanovanjske zazidave (naselje Murgle v Ljubljani), skandinavski sistem moderne laboratorijske kuhinje (SVEA) ter tečaje Barva in oblika. O švedski izkušnji arhitektov Ivanšek so pisali številni raziskovalci povojne slovenske arhitekture, ${ }^{7}$ posebej pa jo izpostavljajo pisci, ki so bolj poglobljeno predstavljali njuno delo. Prvi daljši članek o Ivanških je leta 1990 napisal Peter Krečič ${ }^{8}{ }^{8}$ v njem je opisal, kakšne so bile okoliščine njunega odhoda na Švedsko in v kakšno delo sta bila tam vpeta. Prva daljša obravnava opusa Ivanškov je bilo diplomsko delo avtorice, ${ }^{9} \mathrm{v}$ katerem je posebno poglavje posvečeno prav njuni švedski

4 O množičnih odhodih slovenskih arhitektov v skandinavske države gl. MALEŠIČ 2013 (op. 3).

5 Zlasti Fran ŠIJANEC, Sodobna slovenska likovna umetnost, Maribor 1961; Stane BERNIK, Nekateri problemi predstavitve in vrednotenja sodobne slovenske arhitekture, urbanizma in oblikovanja, Slovenska likovna umetnost 1945-1978, 1, Ljubljana 1979, str. 100; Jelka PIRKOVIČ-KOCBEK, Izgradnja sodobnega Maribora. Mariborska arhitektura in urbanizem med leti 1918 in 1976, Ljubljana 1982; Breda MIHELIČ, Urbanistični razvoj Ljubljane, Ljubljana 1983; Nataša KOSELJ, Arhitektura 60-ih let v Sloveniji. Kontinuiteta ideje, Ljubljana 1995, $(=A B$. Arhitektov bilten, 25), str. 27-28; Stane BERNIK, Slovenska arhitektura dvajsetega stoletja, Ljubljana 2004. Posebej s tematiko skandinavskega vpliva na slovensko arhitekturo se ukvarjata tudi dve neobjavljeni študijski deli: Anja GOLEC, Skandinavski vplivi na slovensko arhitekturo, urbanizem in oblikovanje v petdesetih in šestdesetih letih, Ljubljana 1998 (tipkopis diplomske naloge); MALEŠIČ 2013 (op. 3). Mestoma opozarjajo na ključne stike s Skandinavijo tudi monografske publikacije. Metka Dolenec Šoba v monografiji o Savinu Severju, vrstniku Ivanškov, poudarja pomembno vlogo profesorja Ravnikarja, ki je svoje študente seznanjal s sodobnimi svetovnimi smernicami, s poudarkom na skandinavski arhitekturi (Metka DOLENEC, Savin Sever arhitekt, Ljubljana 2003, str. 36). Andrej Mercina v knjigi o Iliji Arnautoviću omenja povezanost slovenske arhitekture s skandinavsko in poudarja vpliv Švedske na zasnovo slovenskih povojnih sosesk (Andrej MERCINA, Arhitekt Ilija Arnautović. Socializem v slovenski arhitekturi, Ljubljana 2006, str. 9, 20, 79). O vplivu skandinavskega oblikovanja gl. tudi posebno poglavje v monografiji o Niku Kralju: Jasna HROVATIN, Niko Kralj, Ljubljana 2010, str. 84-86.

6 O arhitektih Ivanšek gl. Martina MALEŠIČ, Arhitekta France in Marta Ivanšek, Ljubljana 2008 (tipkopis diplomske naloge).

7 Mdr. ŠIJANEC 1961 (op. 5), str. 472, 478, 492; KOSELJ 1995 (op. 5), str. 12, 27, 41.

8 Peter KREČIČ, France in Marta Ivanšek. Ambientalni okvir za sodobno kvaliteto življenja, Sinteza, 83-86, oktober 1990, str. 73-86.

9 MALEŠIČ 2008 (op. 6), str. 25-30. 
izkušnji. Veliko lahko o njunem bivanju na Švedskem izvemo tudi iz nekaterih intervjujev, ki so jih $\mathrm{z}$ arhitektoma opravile Alenka Lobnik-Zorko, ${ }^{10}$ Nada Ravter ${ }^{11}$ in Nataša Koselj. ${ }^{12}$ Kratke preglede njunega dela in opozorila na vlogo Švedske najdemo tudi v krajših prispevkih Petra Krečiča ob podelitvi nagrade IKEA, ${ }^{13}$ Boga Zupančiča ob Ivanškovi osemdesetletnici ${ }^{14}$ in Vladimirja Braca Mušiča ${ }^{15}$ ter Nataše Koselj ${ }^{16}$ ob Ivanškovi smrti. Prav to obdobje življenja arhitektov Ivanšek je tako večkrat izpostavljeno, a z izjemo krajših omemb še ni bilo podrobno raziskano in predstavljeno. Zato je vpogled v leta, ki sta jih Ivanška preživela v Stockholmu, kaj sta tam videla in v kakšno delo sta bila vpeta, več kot potreben. Poskus rekonstrukcije švedske izkušnje temelji na različnih virih, na lastnih zapisih arhitektov in korespondenci ${ }^{17}$ ter na arhivskem gradivu iz birojev, v katerih sta bila Ivanška v Stockholmu zaposlena. ${ }^{18}$

\section{Leta v Stockholmu}

Arhitekta Ivanšek sta na Švedskem bivala med letoma 1954 in 1959 (sl. 1). V Stockholm sta odšla takoj po zaključku študija leta 1954, sprva le na šestmesečno prakso, ostala pa sta pet let. France Ivanšek se je še pred diplomo s priporočilom profesorja Edvarda Ravnikarja in švicarskega arhitekta Maxa Billa ${ }^{19}$ potegoval za strokovno prakso v Skandinaviji. ${ }^{20}$ Zanimala ga je predvsem Švedska. Že kot urednik revije Arhitekt ${ }^{21}$ in pisec vanjo je objavljal ocene knjig švedskih avtorjev, iz italijanske revije Urbanistica je črpal poročila o novih švedskih gradnjah itd. ${ }^{22}$ Skandinavija je bila zanj vzor

10 Alenka LOBNIK-ZORKO, Skandinavci so pisali o njima, Naša žena, 47/4, 1987, str. 18-19.

11 Nada RAVTER, V Murglah ni padel niti en sam plot, 7D, 18/36, 7. 9. 1989, str. 15-16.

12 Nataša KOSELJ, Potrebe navadnih ljudi. Intervju s Francetom Ivanškom, Emzin, 9/3-4, december 1999, str. $36-41$.

13 Peter KREČIČ, Vsakdanja ambientalna arhitektura, Delo, 28/252, 28. 10. 1986, str. 6.

14 Bogo ZUPANČIČ, Predana kakovosti bivanja, Delo, 44/268, 21. 11. 2002, str. 8.

15 Vladimir Braco MUŠIČ, France Ivanšek. 1922-2007, Delo, 49/50, 2. 3. 2007, str. 23.

16 Nataša KOSELJ, Ob smrti Franceta Ivanška, AB. Arhitektov bilten, 173-174, november 2007, str. 112-115.

17 Ivanškovo bogato korespondenco z družino in prijatelji ter osnutek njegovega življenjepisa hrani zasebni arhiv Ustanove France in Marta Ivanšek. Nekaj korespondence hrani tudi arhiv Muzeja za arhitekturo in oblikovanje (MAO), zbirka Edvarda Ravnikarja.

18 Večino gradiva hrani Švedski center za arhitekturo in oblikovanje ArkDes (Svenskt arkitektur- och designcentrum) v Stockholmu.

19 Švicarski arhitekt Max Bill (1908-1994), dolgoletni rektor arhitekturnega oddelka Visoke šole za oblikovanje v Ulmu, je bil v Ravnikarjevem krogu priljubljen in poznan, pisal je tudi za revijo Arhitekt. Sodeč po večletni korespondenci, ki jo hranijo v arhivu Ustanove France in Marta Ivanšek, je z Ivanškom še posebej tesno prijateljeval. O Maxu Billu gl. Hans FREI, Max Bill, Grove Art Online, https://www.oxfordartonline.com/groveart/ view/10.1093/gao/9781884446054.001.0001/oao-9781884446054-e-7000008883?rskey=lEILqj\&result=1 (12. 10. 2020).

20 Zasebni arhiv Ustanove France in Marta Ivanšek, France Ivanšek: osnutek prispevka za Zbornik ljubljanske univerze 1945-1960. Na delo v tujino naj bi bila po Ivanškovih besedah odšla predvsem zaradi takratnih delovnih pogojev v Sloveniji. Služb namreč ni bilo veliko, še te pa so bile menda vezane predvsem na ministrstvo za gradnje, ki pa mladih arhitektov ni podpiralo.

21 Revija Arhitekt. Revija za arhitekturo, urbanizem in oblikovanje izdelkov je izhajala od leta 1951 do leta 1963, izdajalo jo je Društvo arhitektov Slovenije, od leta 1960 pa Zveza arhitektov Slovenije v Ljubljani. France Ivanšek je bil urednik revije v letih 1951-1954 in 1960.

22 France IVANŠEK, O današnji usmerjenosti švedske arhitekture in urbanizma, Arhitekt, 3/10, 1953, str. 43-45. 


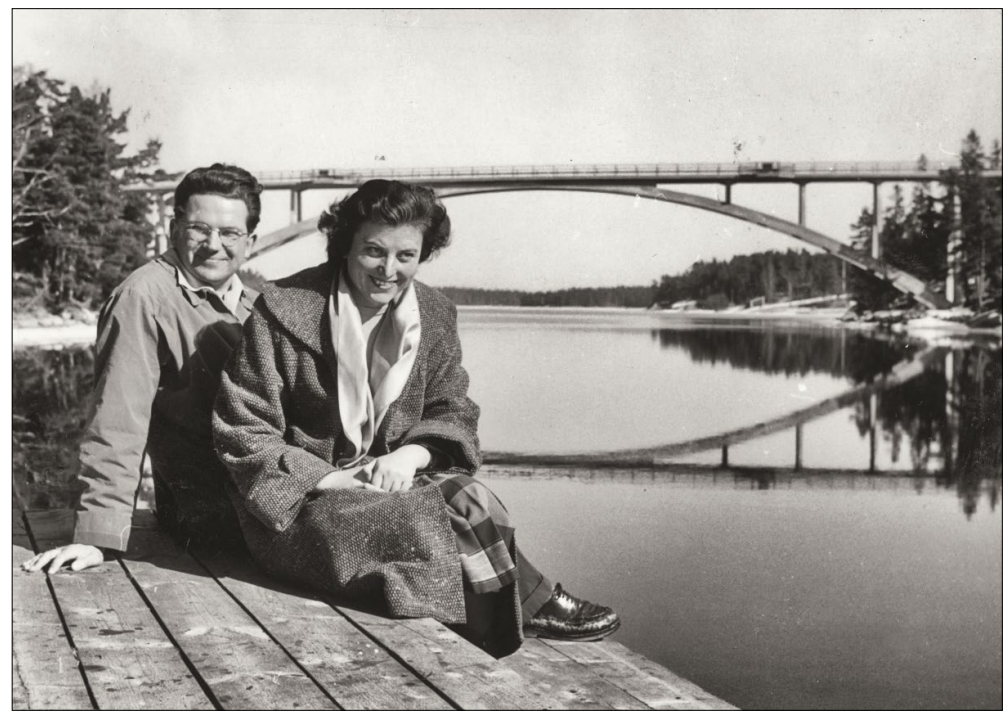

1. France in Marta Ivanšek pod mostom Traneberg, Stockholm, med 1954 in 1959

bolj humanističnega pristopa h gradnji stanovanj, s katerim so bili po njegovih besedah "prežeti vsi za napredek zavzeti mladi slovenski arhitekti«. ${ }^{23}$ Švedska mu je bila blizu tudi po svojem razumevanju in reševanju socialnih vprašanj. ${ }^{24}$ En mesec pred diplomskim izpitom je dobil sporočilo, da je za šest mesecev sprejet na prakso $v$ arhitekturni oddelek švedske stanovanjske zadružne zveze HSB (Hyresgästernas sparkasse- och byggnadsförening). ${ }^{25}$ Le sedem dni po zagovoru diplomske naloge, junija 1954, se je z ženo Marto, tudi arhitektko, sicer mlajšo sestro profesorja Ravnikarja, odpravil v Stockholm (sl. 2). ${ }^{26}$ Na poti sta se ustavila še v Ulmu pri Maxu Billu, ki jima je razkazal gradnjo Visoke šole za oblikovanje (Hochschule für Gestaltung), in v Københavnu pri profesorju Ejnarju Borgu ${ }^{27}$ Ravnikarjevem prijatelju iz časa risanja v Le Corbusierjevem ateljeju v Parizu. Ivanšek je sicer načrtoval, da bi se po zaključeni praksi v Stockholmu vrnil nazaj v Ulm na Billovo Visoko šolo za oblikovanje, ${ }^{28}$ vendar sta zakonca Ivanšek na Švedskem ostala veliko dlje, kot sta načrtovala - svoje bivanje sta s šestih mesecev podaljšala na pet let.

23 France IVANŠEK, Družina, stanovanje in naselje. Anketna raziskava 195 stanovanj v Savskem naselju v Ljubljani (1961), Ljubljana 1988, str. 9.

24 France IVANŠEK, Stanovanjsko raziskovanje na Švedskem, Naši razgledi, 8/10, 30. 5. 1959, str. 247-248.

25 Zasebni arhiv Ustanove France in Marta Ivanšek, Korespondenca, pismo Franceta Ivanška Vladimirju Bracu Mušiču, 1. 8. 1954. HSB, Najemniška hranilna in gradbena zveza, je bila državna organizacija, zadolžena za stanovanjsko gradnjo in opremo. Ustanovljena je bila leta 1923. V štiridesetih letih je doprinesla k izoblikovanju norm pohištva, posameznih prostorov in odnosov med njimi. Po letu 1945 je prevzela vodilno vlogo v stanovanjski politiki. Opravljala je tako projektantske kot gradbene in finančne naloge; gl. France IVANŠEK, Osnovne poteze skandinavske stanovanjske politike, Arhitekt, 5/16, 1955, str. 38; Eva RUDBERG, Building the Welfare of the Folkhemmet 1940-60, 20 $0^{\text {th }}$-Century Architecture. Sweden (ur. Claes Caldenby, Jöran Lindvall, Wilfried Wang), München-New York-Frankfurt am Main-Stockholm 1998, str. 112, 117.

26 KREČIČ 1990 (op. 8), str. 80.

27 Danski arhitekt Ejnar Borg (1912-1978) je delal v ateljeju arhitektov Le Corbusierja in Pierra Jeannereta na Rue de Sèvres 35 v Parizu sočasno z Ravnikarjem leta 1939. Gl. Bogo ZUPANČIČ, Plečnikovi študenti in drugi jugoslovanski arhitekti v Le Corbusierovem ateljeju, Ljubljana 2017, str. 80.

28 Zasebni arhiv Ustanove France in Marta Ivanšek, Korespondenca, pismo Franceta Ivanška Mitji Jernejcu, 16. 1. 1955. 


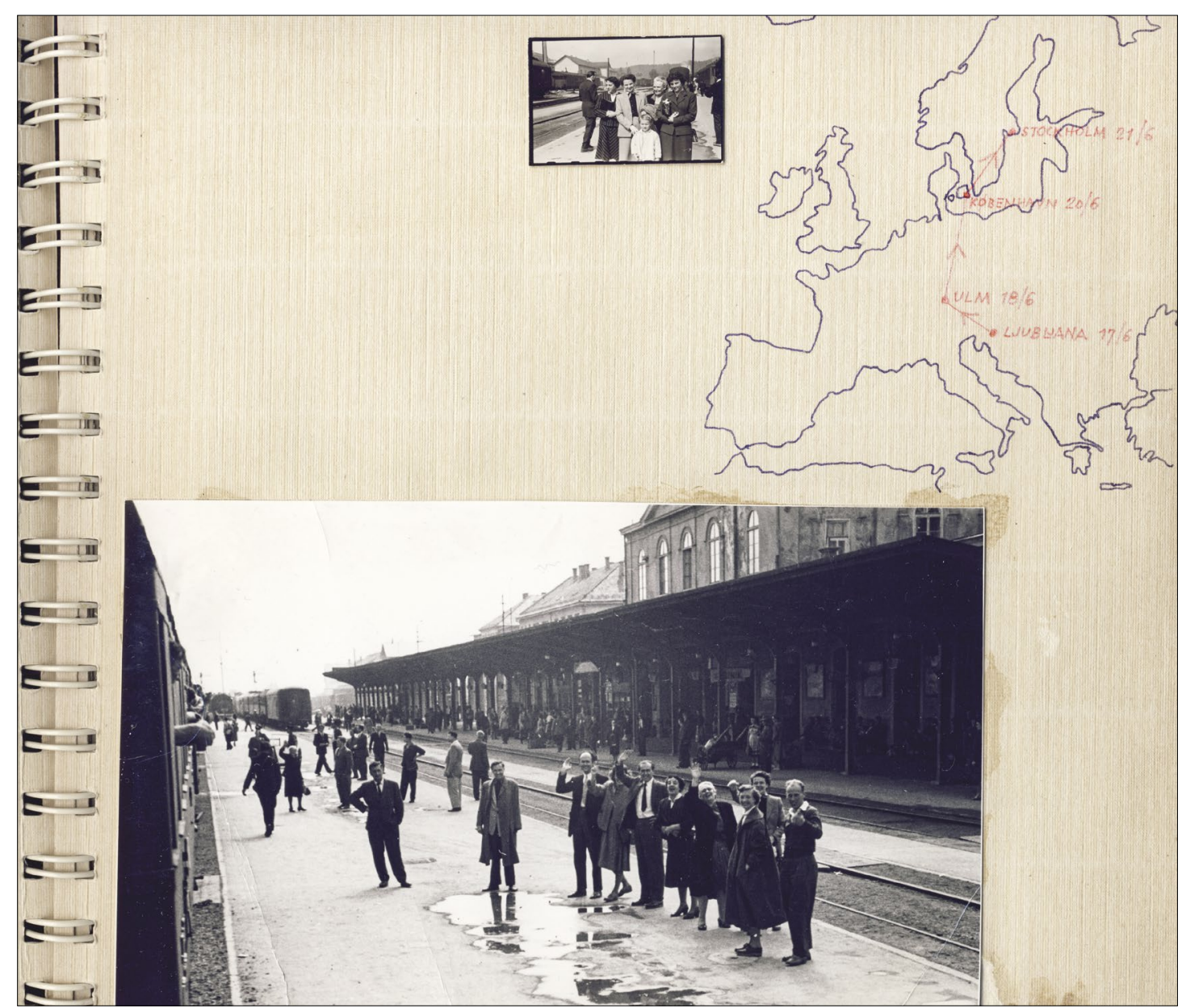

2. Stran iz fotoalbuma Ivanškov z izrisano potjo $v$ Stockholm ter fotografijo poslavljanja od prijateljev in družine na ljubljanski železniški postaji 17. junija 1954 (od leve proti desni stojijo Edvard Ravnikar, Stanko Kristl, Ilija Arnautović, Daša Pelhan, Boris Gabeř̌čik, Mica Ravnikar, Ivanškova mati in sestra, Beba Dečman in Mitja Jernejec)

Pri HSB je Ivanšek vztrajal nekaj več kot dva meseca. V biroju arhitekta Billa Engströma Johanssona ${ }^{29}$ je sodeloval pri projektu stolpnice $\mathrm{v}$ Jönköpingu, ${ }^{30} \mathrm{ob}$ tem pa spoznaval značilnosti švedske zadružne stanovanjske gradnje. Delo pri HSB je bilo Ivanšku sprva všeč, kmalu pa je opazil »tudi nesimpatično, n.pr. prilično uradniško, nekreativno vzdušje, ki je verjetno neizogibno pri vseh tako velikih birojih «. ${ }^{31}$ Motila ga je prevelika množica standardov, ${ }^{32}$ HSB se mu je zdela tudi preveč tradicionalna in strokovno razbita. ${ }^{33}$ Zato so ga veliko bolj privlačili zasebni biroji.

29 Švedski arhitekt Bill Engström-Johansson (1917-1979) je bil med letoma 1951 in 1979 zaposlen pri HSB. Gl. Engström-Johansson, Bill, Vem är vem. Stor-Stockholm (ur. Paul Harnesk), Stockholm 1962, str. 348.

30 Poleg Ivanškovega pričevanja potrjuje njegovo zaposlitev pri HSB tudi seznam zaposlenih iz leta 1954; gl. HSB 30 ÅR (ur. Lennart Holm), Stockholm 1954, str. 272.

31 Zasebni arhiv Ustanove France in Marta Ivanšek, Korespondenca, pismo Franceta Ivanška Vladimirju Bracu Mušiču, 1. 8. 1954.

32 Zasebni arhiv Ustanove France in Marta Ivanšek, Korespondenca, pismo Franceta Ivanška Vladimirju Bracu Mušiču, 1. 8. 1954.

33 KREČIČ 1990 (op. 8), str. 80. 
Septembra 1954 je zamenjal službo. Zaposlil ga je arhitekt Carl-Axel Acking, ${ }^{34}$ profesor za pohištvo na visoki šoli za oblikovanje v Stockholmu, ki je imel skupaj z arhitektom Svenom Hesselgrenom biro $\mathrm{z}$ desetimi sodelavci. ${ }^{35} \mathrm{Vključil} \mathrm{se} \mathrm{je} \mathrm{v}$ njihove priprave na veliko mednarodno razstavo stanovanjske kulture H-55 leta 1955 v Helsingborgu. ${ }^{36}$ Razstava je prikazala oblikovanje človekovega bivalnega okolja in tako obsegala vse od doma do okolja javnega življenja. Prvi del razstave je obsegal pet enodružinskih hišic $\mathrm{z}$ ekonomično tlorisno rešitvijo brez kleti in $\mathrm{z}$ montažnim načinom gradnje, drugi del okolje javnega življenja, tretji pa stvari okoli nas. Ivanšek je o razstavi za revijo Arhitekt prispeval članek, v katerem je zapisal, da je skandinavski oddelek pokazal svojo najvišjo kakovost, saj "ti izdelki niso samo razstavna, luksuzna roba, dostopna samo poedincem, ampak predstavljajo standard današnjih stvari okoli nas «. ${ }^{37}$ Ivanšek je sodeloval pri izrisu celotne zasnove razstave (sl. 3), pri idejnih načrtih posameznih paviljonov in pri gradnji centralnega gostinskega objekta BAR 55 (sl. 7), ${ }^{38} \mathrm{z}$ načrti in perspektivami pomola, na katerem se je nahajal razstavni prostor, pa je opremil katalog razstave (sl. 4). ${ }^{39} \mathrm{~V}$ arhivu lahko najdemo tudi več Ivanškovih variant nizko-goste stanovanjske zazidave, ki je bila predstavljena na razstavi (sl. 5). ${ }^{40} 26$. junija 1955 je bila slavnostna otvoritev, ki sta se je udeležila tako Ivanška (sl. 6) kot številni ugledni gostje, med drugim švedski kralj Gustav Adolf s kraljico in finski arhitekt Alvar Aalto z ženo Elisso.

Po poletnih počitnicah je Ivanšek v Ackingovem biroju nadaljeval z drugimi projekti, z načrti za modernizacijo banke v Malmöju, detajli za hotel v Östersundu in načrti za družinski hotel ${ }^{41} \mathrm{v}$

34 Carl-Axel Acking (1910- 2001) je bil švedski arhitekt, pisec, oblikovalec pohištva in učitelj. Med letoma 1939 in 1955 je imel arhitekturni biro s Svenom Hesselgrenom, po letu 1955 pa je ustanovil lastno podjetje. Med Ackingovimi pomembnejšimi deli so kapela, Torsby (1950), družinski hotel, Hässelby - Stockholm (1955), »Quality Hotel«, Östersund (1956), Skånska banken och Kreditbanken på Södergatan, Malmö (1965), Birgittakyrkan, Skön (1972). Gl. Acking, Carl-Axel, Vem är det. Svensk biografisk handbok 1973 (ur. Eva Löwgren), Stockholm 1972, str. 3; Acking, Carl-Axel (1910-2001), DigitaltMuseum, https://digitaltmuseum.org/011034075658/acking-carlaxel-1910-2001 (12. 10. 2020).

35 Zasebni arhiv Ustanove France in Marta Ivanšek, Korespondenca, pismo Franceta Ivanška Vladimirju Bracu Mušiču, 7. 11. 1954.

36 Mednarodna razstava H-55 je potekala med 10. junijem in 28. avgustom $1955 \mathrm{v}$ švedskem mestu Helsingborg. $\mathrm{Na}$ njej je sodelovalo devet nacionalnih udeležencev, Danska, Finska, Francija, Japonska, Norveška, Švedska, Švica, Združeno kraljestvo in Zahodna Nemčija. Posvečena je bila arhitekturi, oblikovanju in opremi doma, njene središčne teme pa so bile uporabnost, preprostost in lepota oblikovanja. Z opaznim nastopom skandinavskih oblikovalcev se je razstava uspešno vključila v sočasno uveljavljanje vodilne vloge nordijskih držav na področju oblikovanja. Več o razstavi v njenem katalogu: Bo Gunnar LINDGREN, H55, Hälsingborg Exhibition 1955. International Exhibition of Architecture, Industrial Design, Home Furnishings and Crafts, Hälsingborg 1955.

37 France IVANŠEK, H55 - mednarodna razstava stanovanj, opreme in umetniške industrije, Arhitekt, 6/18-19, 1956, str. 47.

38 Zasebni arhiv Ustanove France in Marta Ivanšek, Korespondenca, pismo Franceta Ivanška Vladimirju Bracu Mušiču, 7. 11. 1954.

39 ArkDes, Carl-Axel Acking, mapa 3, AM 1988-04-15, H55 perspektiv skisser.

40 ArkDes, Carl-Axel Acking, mapa 3, AM 1988-04-21, H55 hantverkets hus.

41 Pojem družinskega hotela, posebnega tipa kolektivne hiše, namenjene družini, je kot specifičen skandinavski fenomen opisal Mitja JERNEJEC, Razvoj kolektivnih hiš, Naši razgledi, 6/23, 14. 12. 1957, str. 587-589. Podobni primeri so se pojavljali tudi drugod po svetu. Prva kolektivna hiša je bila postavljena leta 1903 v Københavnu. V Sovjetski zvezi so v dvajsetih letih gradili t. i. komunske hiše, kjer so s skupnimi pralnicami in kuhinjami želeli sprostiti delo gospodinj in s tem pridobiti več delovne sile za industrijo. Bolj hotelom podobne zamisli so nastajale v Angliji in ZDA, v tridesetih letih pa tudi drugje po Evropi. Na Švedskem so se t. i. »družinski hoteli« začeli množiti v petdesetih letih, predvsem iz praktičnih razlogov: razbremeniti zaposlene ženske in omogočiti višji porast natalitete. Kolektivne hiše naj bi nudile najrazličnejša stanovanja, od takih za eno osebo do srednjih in največjih. Organizirana naj bi bila skupna prehrana, pranje perila v danih prostorih in varstvo otrok. 

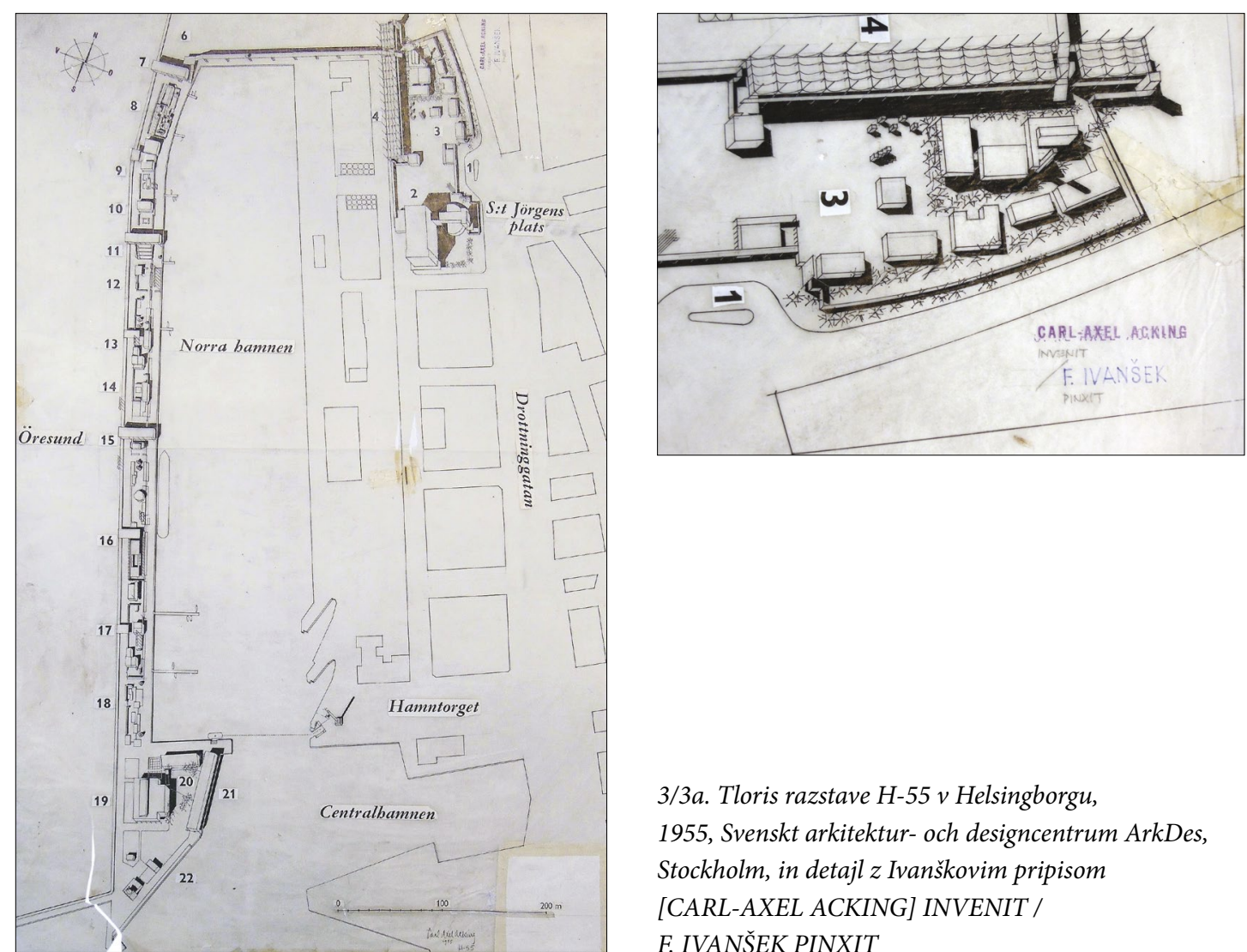

3/3a. Tloris razstave $H-55$ v Helsingborgu, 1955, Svenskt arkitektur- och designcentrum ArkDes, Stockholm, in detajl z Ivanškovim pripisom [CARL-AXEL ACKING] INVENIT / F. IVANŠEK PINXIT

4/4a. France Ivanšek: perspektivni risbi vhoda in glavnega paviljona za katalog mednarodne razstave stanovanjske kulture H-55 v Helsingborgu, 1954, Svenskt arkitektur-och designcentrum ArkDes, Stockholm
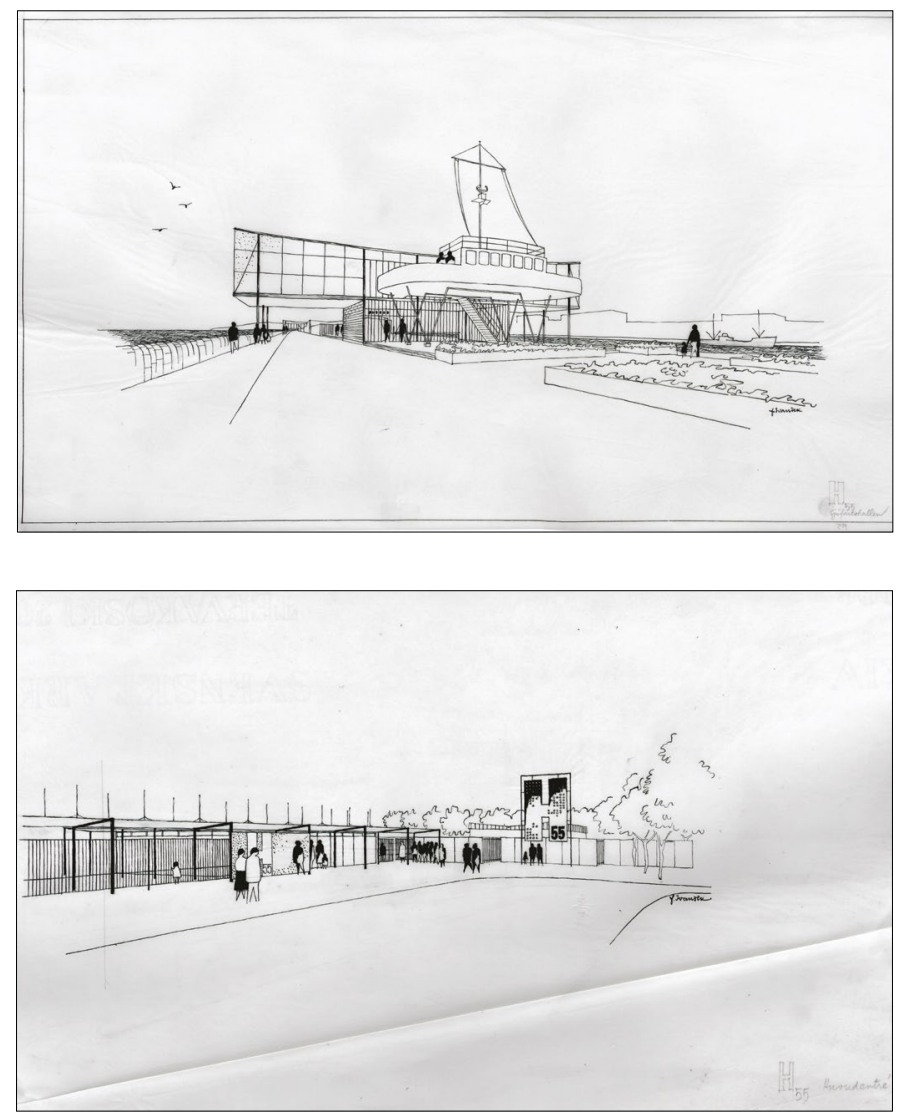


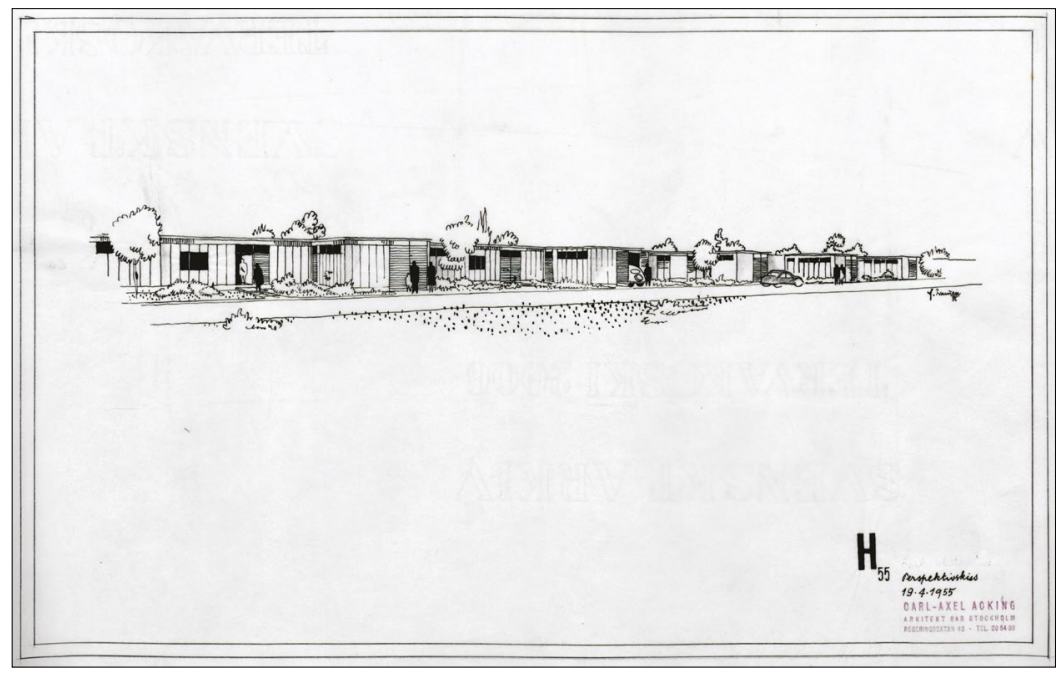

5. France Ivanšek: risba verižnih hiš za razstavo $H-55$ $v$ Helsingborgu, 1955, Svenskt arkitektur- och designcentrum ArkDes, Stockholm

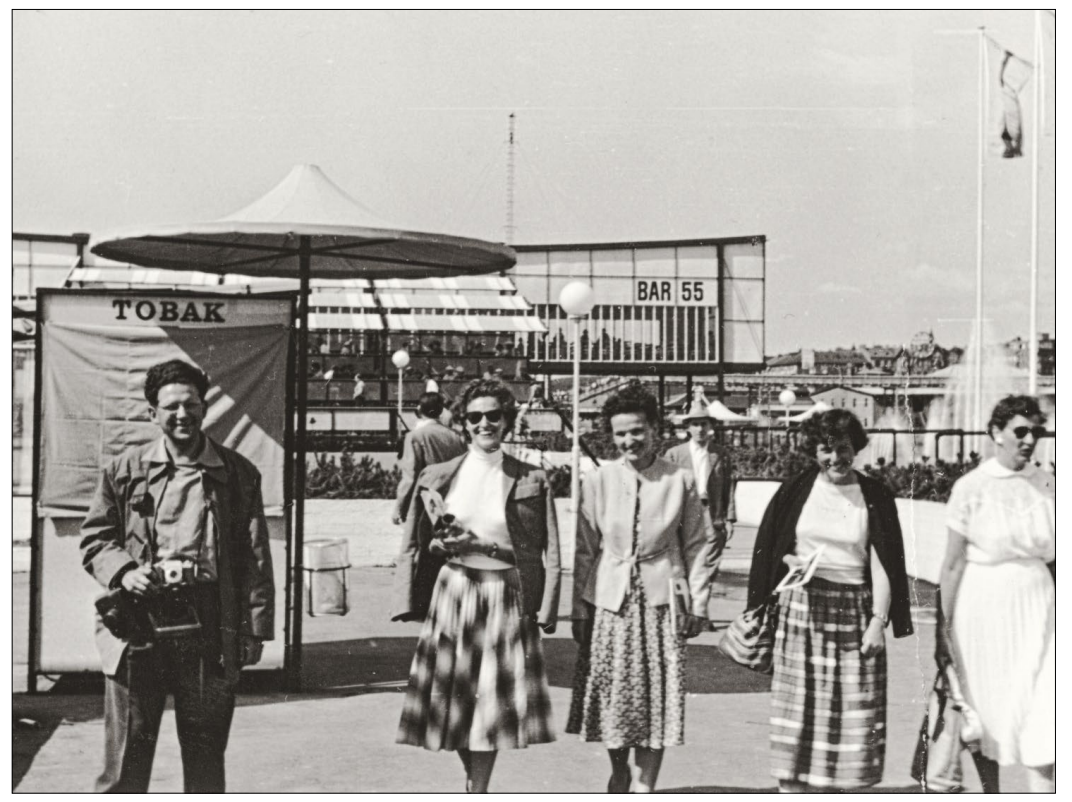

6. France (skrajno levo) in Marta Ivanšek (skrajno desno) na otvoritvi razstave H-55 v Helsingborgu, 26. junij 1955

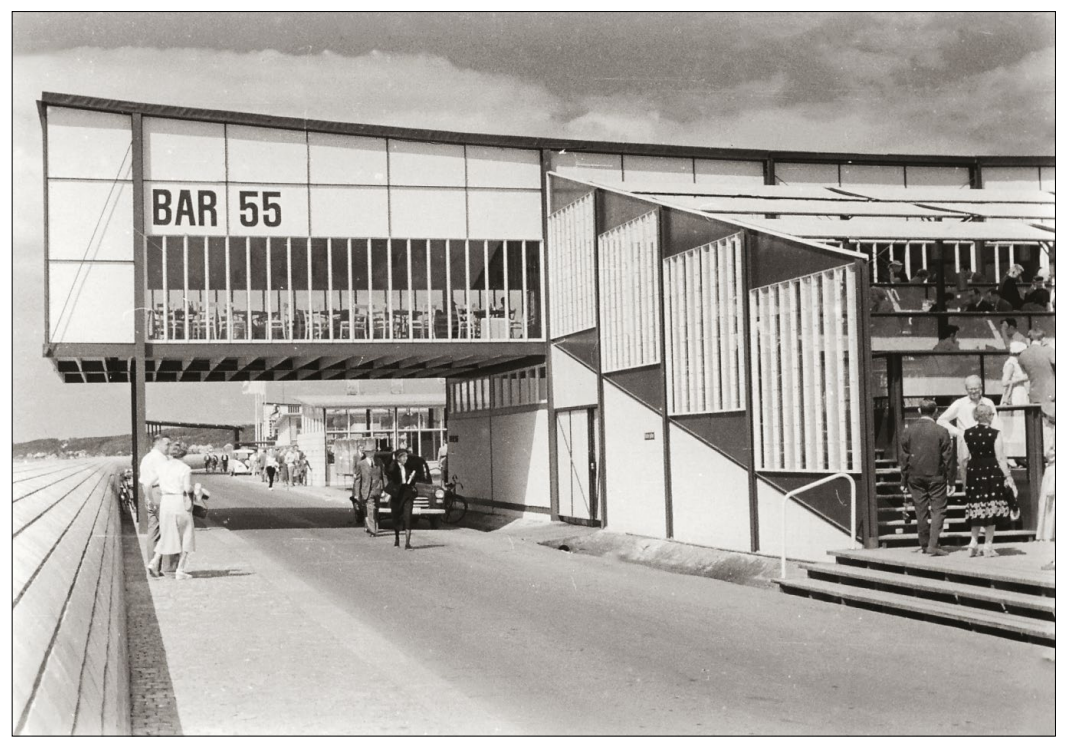
$B A R$ 55, razstava $H-55$ v Helsingborgu, 1955 

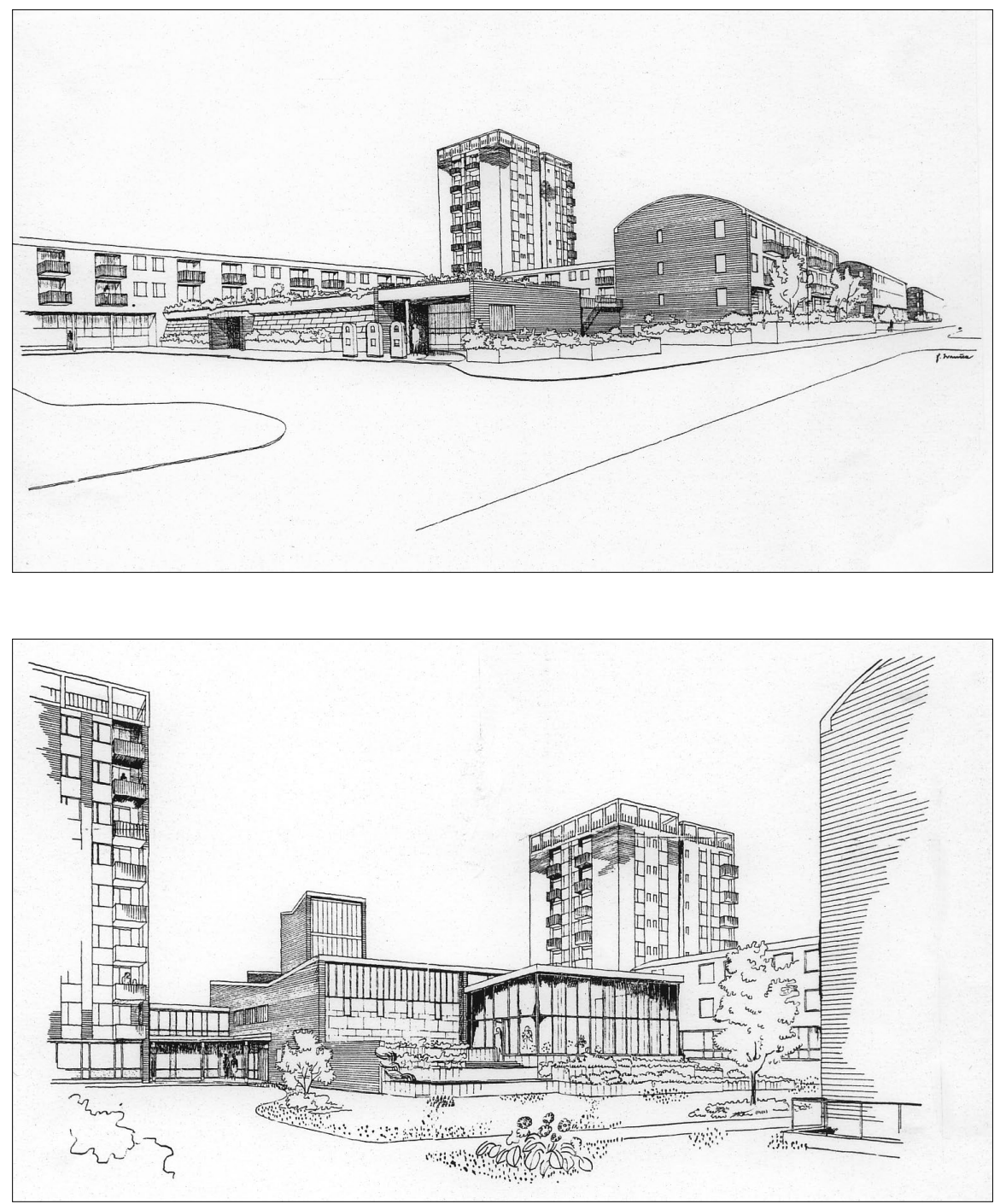

8/8a. France Ivanšek: perspektivni risbi za družinski hotel Hässelby v Stockholmu, 1955,

Svenskt arkitektur- och designcentrum ArkDes, Stockholm

Hässelbyju pri Stockholmu. Tudi za ta projekt so v arhivu ArkDes ohranjene perspektivne risbe z Ivanškovim podpisom (sl. 8). ${ }^{42}$ Hotel v Hässelbyju je bil zgrajen v neposredni bližini znanega naselja Vällingby, ki je v petdesetih letih predstavljalo množično obiskan dosežek napredne švedske stanovanjske gradnje. Hotel določa več urbanističnih in projektantskih principov, ki so spremljali Ivanška v njunem kasnejšem opusu, predvsem pri naselju Murgle: kolektivna stanovanjska gradnja, človeško merilo, objekti manjših višin, vključevanje zelenja, nenazadnje pa tudi v Murglah prepoznavna kombinacija vidne opeke in belega ometa. Pri Ackingu je Ivanšek izrisal tudi idejni projekt za osnovno šolo v Norrköpingu, ${ }^{43}$ pri katerem je sodeloval Mitja Jernejec, Ravnikarjev asi-

42 ArkDes, Carl-Axel Acking, mapa 66, AM 1988-04-423, Hässelby familjehotell.

43 Zasebni arhiv Ustanove France in Marta Ivanšek, Korespondenca, pismo Franceta Ivanška Vladimirju Bracu Mušiču, 5. 2. 1956. 
stent, v času, ko je med svojim bivanjem na Švedskem tudi on delal v Ackingovem biroju. ${ }^{44}$ To naj bi bil Ivanškov zadnji projekt, saj se je že dogovoril za novo službo v Biroju za vodne gradnje (VBB), ki ga je vodil urbanist Sune Lindström. V njihovem arhitekturnem oddelku naj bi sodeloval pri prihajajočem projektu za stanovanjsko naselje Täby. ${ }^{45}$ Tega se je srčno veselil, saj so bila stanovanja tisto, kar si je želel delati že od začetka, pa za to še ni imel priložnosti. ${ }^{46} \mathrm{Kljub}$ načrtom očitno do zamenjave ni prišlo, saj v pismih s kasnejšim datumom piše o tem, da se je pod Ackingovim okriljem, a samostojno, udeležil natečaja za športno in plavalno halo v Fagersti. ${ }^{47}$ Nato se je lotil natečaja za urbanistično rešitev stanovanjskega naselja Fiskartorpet v mestu Finspång. ${ }^{48}$ Sledila je naloga za naselje z okoli 60 vrstnimi hišami v Farsti, južno od Stockholma. ${ }^{49}$ Udeležil se je tudi natečaja za naselje 200 enodružinskih hiš v Saltsjöbadenu. Ob tem je poročal, da je pri vsem naštetem delu zaenkrat sam in da še ni prišlo do izgradnje katerega od njegovih projektov. ${ }^{50}$ Poleg tega je tožil, da še ni imel priložnosti priti preko enonadstropnih hiš, tako da mu bloki ostajajo še neizpolnjena točka v švedskem programu. ${ }^{51} \mathrm{Ta}$ želja se mu je izpolnila kasneje, ko je sodeloval pri stanovanjskem naselju v Enköpingu, ki naj bi ga začeli graditi maja 1957. Obsegalo je en devetnadstropni blok, deset vrstnih hiš in štirinadstropne bloke. ${ }^{52}$

Maja 1957 je zaradi želje po spremembi ${ }^{53}$ odšel v biro Ahlström-Bryde-Äström, ${ }^{54} \mathrm{ki}$ so ga vodili arhitekti Åke Ahlström, Lars Bryde in Kell Äström (sl. 9). Tam je ostal do jeseni 1959, v tem času pa je sodeloval pri številnih stanovanjskih projektih: pri velikem stanovanjskem naselju Tanto $\mathrm{v}$ Stockholmu (sl. 10) z dvema velikima blokoma s 7 in 13 nadstropji, pri tipskih enodružinskih hišah za Myresjö, vrstnih hišah v Farsti in Saltsjöbadnu, pri stanovanjskem kompleksu Garvaren v Enköpingu in pri dekliškem vzgojnem centru v Lovsätri. ${ }^{55}$ Vse našteto je delal v službi pod tujim imenom, doma $\mathrm{v}$ večernih urah pa se je pod lastnim imenom $\mathrm{z}$ neko kolegico lotil paviljona za

44 MALEŠIČ 2013 (op. 3), str. 76.

45 Zasebni arhiv Ustanove France in Marta Ivanšek, Korespondenca, pismo Franceta Ivanška Branki Tancig, 29. 1. 1956; Zasebni arhiv Ustanove France in Marta Ivanšek, Korespondenca, pismo Franceta Ivanška Vladimirju Bracu Mušiču, 5. 2. 1956.

46 Zasebni arhiv Ustanove France in Marta Ivanšek, Korespondenca, pismo Franceta Ivanška Vladimirju Bracu Mušiču, 5. 2. 1956.

$47 \mathrm{~V}$ Ackingovi zapuščini hranijo tudi projekt za športno dvorano (izrisi fasad, tlorisi, perspektive, fotografije makete), ki sicer ni podpisan, vendar lahko na njem prepoznamo malce bolj okorno Ivanškovo risbo in rokopis; gl. ArkDes, Carl-Axel Acking, mapa 84, AM 1988-04-508, sim- och idrottshall i Fagersta.

48 Zasebni arhiv Ustanove France in Marta Ivanšek, fotokopije perspektivnih skic naselja Finspång.

49 ArkDes, Carl-Axel Acking, mapa 23, AM 1988-04-98, radhus, Farsta. Gradivo priča o Ivanškovem sodelovanju pri projektu, ponekod se pojavljajo podpisi, drugje njegov rokopis.

50 Zasebni arhiv Ustanove France in Marta Ivanšek, Korespondenca, pismo Franceta Ivanška Vladimirju Bracu Mušiču, 13. 12. 1956.

51 Zasebni arhiv Ustanove France in Marta Ivanšek, Korespondenca, pismo Franceta Ivanška Vladimirju Bracu Mušiču, 13. 12. 1956.

52 Zasebni arhiv Ustanove France in Marta Ivanšek, Korespondenca, pismo Franceta Ivanška Vladimirju Bracu Mušiču, 6. 1. 1957.

53 Zasebni arhiv Ustanove France in Marta Ivanšek, Korespondenca, pismo Franceta Ivanška Vladimirju Bracu Mušiču, 29. 8. 1957.

54 Arhitekturni biro Ahlström-Bryde-Äström so vodili Åke Ahlström (1918-2001), Lars Bryde (1918-2002) in Kell Äström (1920-2004), deloval je med letoma 1953 in 1959. Gl. Ahlström, Åke (1918-2001), DigitaltMuseum, https://digitaltmuseum.org/011034075677/ahlstrom-ake-1918-2001 (12. 10. 2020).

55 KREČIČ 1990 (op. 8), str. 80; Zasebni arhiv Ustanove France in Marta Ivanšek, France Ivanšek: Fragmenti za življenjepis, 6. 6. 2005. 


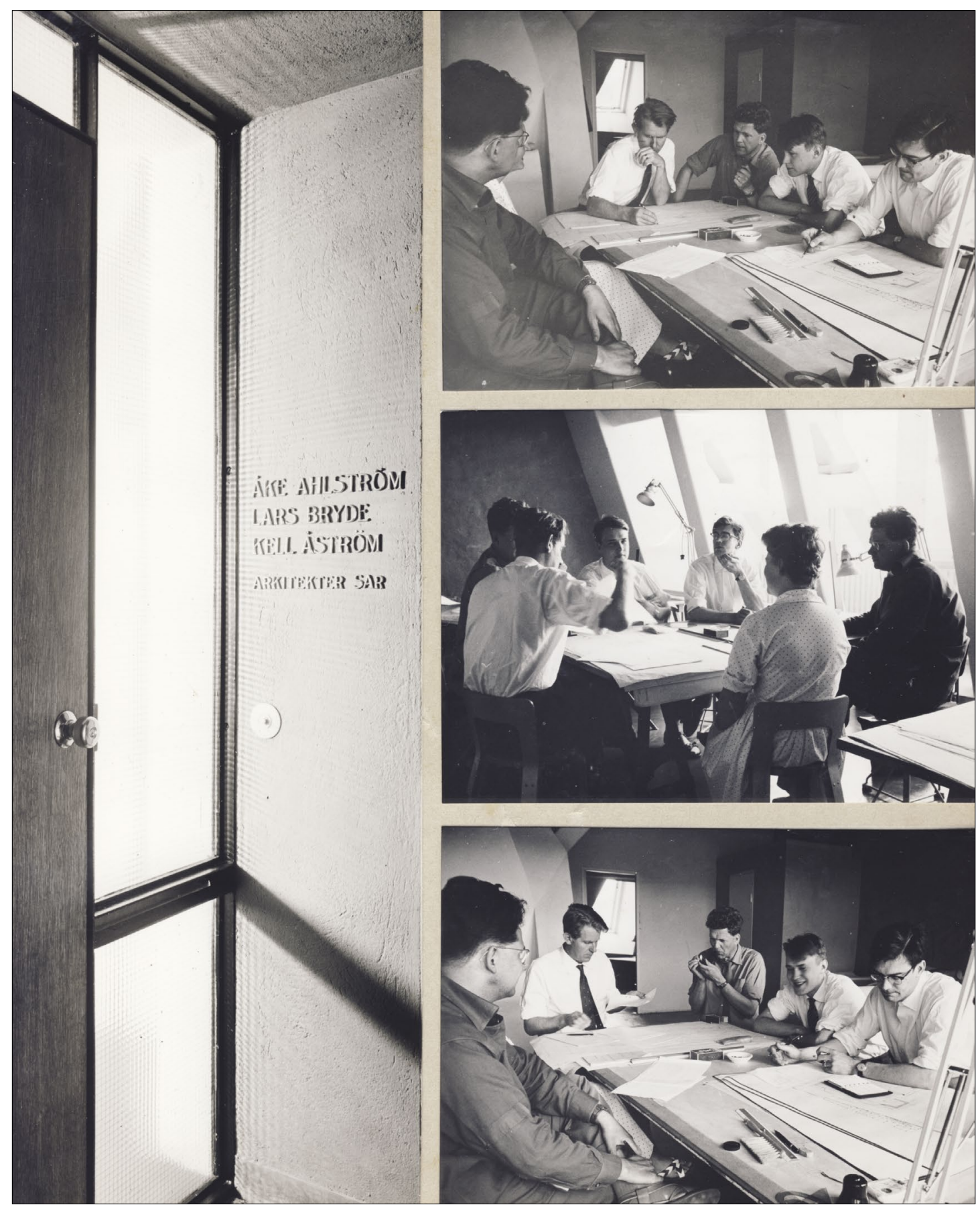

9. Kolaž iz fotoalbuma Ivanškov s posnetki iz biroja Ahlström-Bryde-Åström

(France Ivanšek na zgornji in spodnji fotografiji skrajno levo, na srednji skrajno desno)

mednarodno razstavo merilnih inštrumentov v Stockholmu, z ženo Marto pa sta leta 1956 risala tudi natečajni projekt za jugoslovanski študentski paviljon v Parizu. ${ }^{56}$

56 Zasebni arhiv Ustanove France in Marta Ivanšek, Korespondenca, pismo Franceta Ivanška Branki Tancig, 31.12. 1956; Zasebni arhiv Ustanove France in Marta Ivanšek, France Ivanšek: Fragmenti za življenjepis, 6. 6. 2005. 

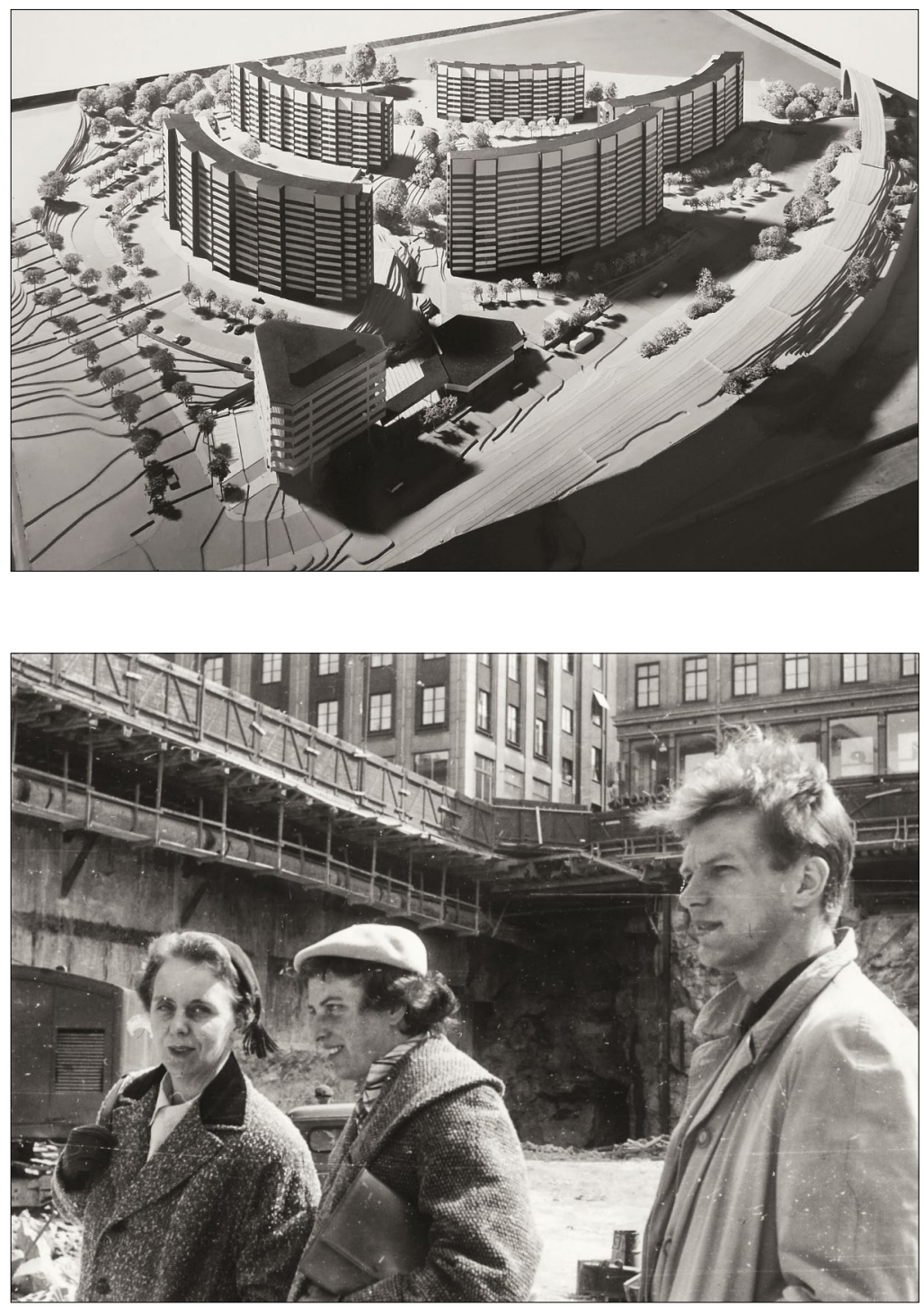

10. Arhitekturni biro Ahlström-Bryde-Äström (sodelavec France Ivanšek): maketa naselja Tanto, 1959, Svenskt arkitektur- och designcentrum ArkDes, Stockholm
11. Marta Ivanšek (v sredini) s sodelavci iz biroja Davida Helldéna na gradbišču Sergelteatra $v$ Stockholmu, 1957

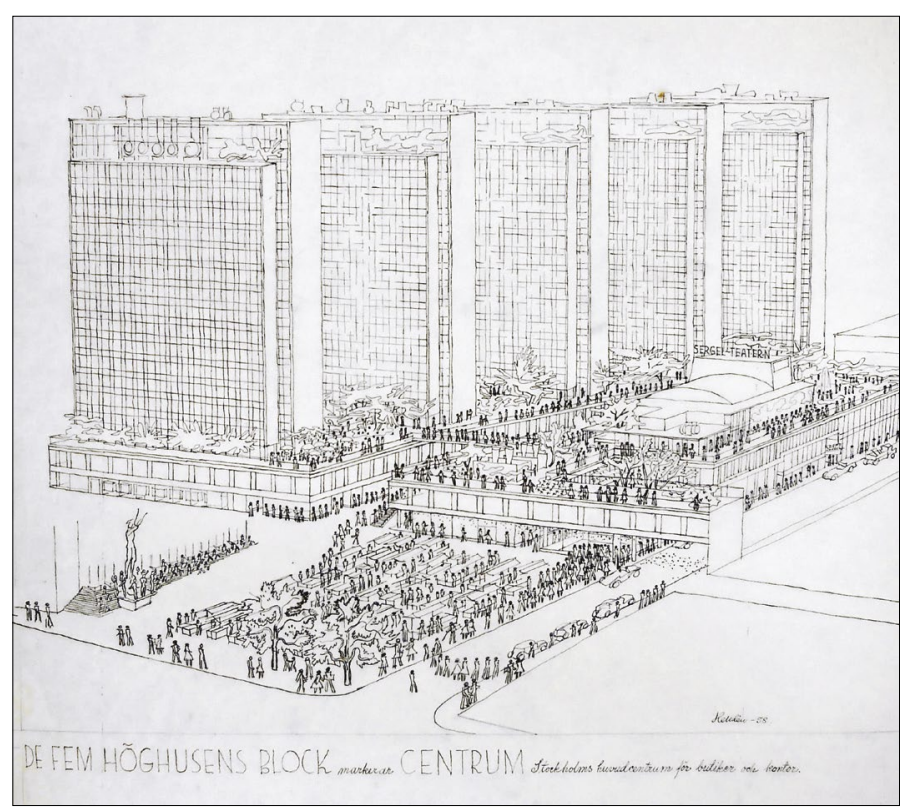

12. David Helldén: skica za novi center Stockholma s Sergelteatrom v ozadju, 1958, Svenskt arkitektur- och designcentrum ArkDes, Stockholm 


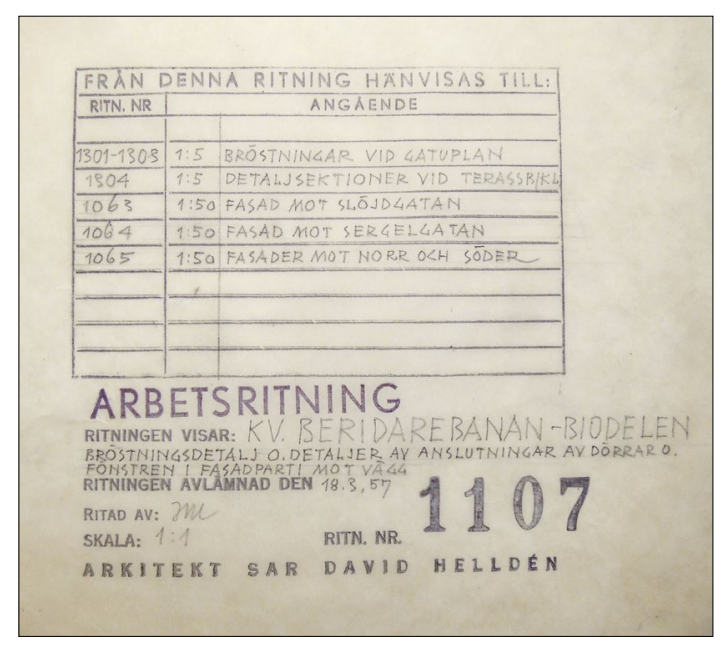

13. Glava načrta detajlov za Sergelteatern $z$ rokopisom in podpisom Marte Ivanšek, 1957, Svenskt arkitekturoch designcentrum ArkDes, Stockholm

Medtem ko lahko Ivanškovo stockholmsko zgodbo s pomočjo podatkov $\mathrm{v}$ intervjujih, korespondenci in arhivskem gradivu dokaj dobro sestavimo $\mathrm{v}$ smiselno celoto, pa je o delu Marte Ivanšek v Stockholmu težko pisati, saj je njenih zapisov malo, sledi $\mathrm{v}$ arhivskem gradivu pa skorajda ni. France Ivanšek je v pismu kolegu arhitektu Borisu Gaberščiku 7. avgusta 1954 pisal, da je Marta sprva načrtovala, da bi delala na Gospodinjskem raziskovalnem inštitutu (Hemens forskniginstitutet), »saj bi ji to omogočilo podroben študij švedske kuhinje, ki je bila po njenem mnenju res imenitna«. ${ }^{57}$ Vendar tega dela očitno ni dobila, saj se je že jeseni leta 1954 za dve leti zaposlila v biroju Davida Helldéna, kjer je bila vključena v izdelavo načrtov za nov trgovski in kulturni center Stockholma (sl. 11). ${ }^{58}$ Sodelovala je predvsem pri izrisovanju načrtov za gledališče Sergel (Sergelteatern, sl. 12) ${ }^{59}$ kar je bila verjetno izjemna izkušnja, saj je Helldén veljal za enega najboljših strokovnjakov za gledališke stavbe na severu. V Helldénovi zapuščini je sicer sled Marte Ivanšek težko zaznati, vendar lahko ponekod, predvsem na glavah projektov za detajle gledališča Sergel, zaznamo njen rokopis in tudi podpis (sl. 13). Po dveh letih je odšla v biro arhitekta Georga Varhelyija, kjer je sodelovala pri načrtih za naselje Berghamra. ${ }^{60} \mathrm{Ob}$ delu, ki ga v korespondenci ni omenjala veliko, se je tudi dodatno izobraževala. V zadnjem poletju na Švedskem se je udeležila seminarja o barvi in obliki v domačem okolju (Färg och Form i Hemmiljö), ki ga je v Uddevalli pri Göteborgu od 9. do 18. julija 1959 vodil švedski arhitekt Erik Berglund. ${ }^{11}$ Večji del predavanj in vaj je bil namenjen barvni teoriji, barvni kompoziciji in uporabi barve v notranji opremi. Obisk seminarja se je izkazal za enega od pomembnejših dogodkov med bivanjem na Švedskem. Marta je v njem prepoznala praktičen sistem, ki bi bil lahko koristen tudi za domačo, slovensko publiko. Na tem modelu zasnovan tečaj, imenovan Barva in oblika, sta Ivanška nekaj let zatem uspešno organizirala doma in $s$ švedsko teorijo naravnega barvnega kroga ter njegovo uporabnostjo v praktičnem življenju močno zaznamovala številne generacije arhitektov, oblikovalcev in tekstilnih delavcev. ${ }^{62} \mathrm{~V}$ Uddevalli se je

57 Zasebni arhiv Ustanove France in Marta Ivanšek, Korespondenca, pismo Franceta Ivanška Borisu Gaberščiku, 7. 8. 1954.

58 Zasebni arhiv Ustanove France in Marta Ivanšek, Korespondenca, pismo Franceta Ivanška Vladimirju Bracu Mušiču, 7. 11. 1957.

59 ArkDes, David Helldén, mapa 3, AM 1990-32, Hötorgscity, Sergelteatern.

60 KREČIČ 1990 (op. 8), str. 83.

61 KREČIČ 1990 (op. 8), str. 84.

62 MALEŠIČ 2013 (op. 3), str. 152-154. 


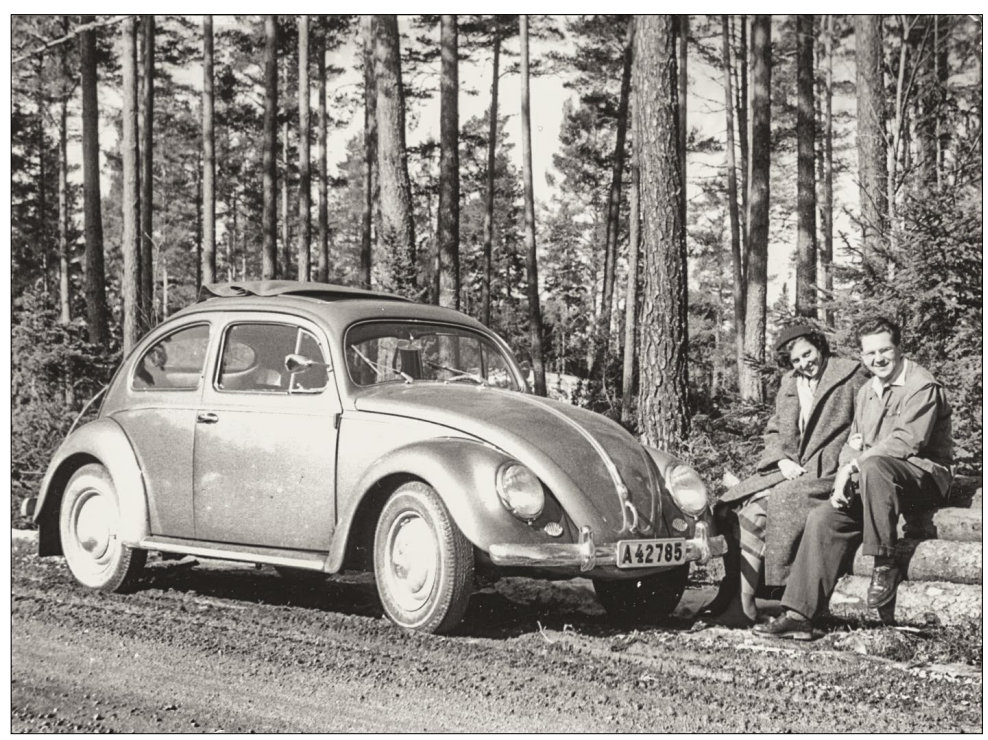

14. Marta in France Ivanšek s svojim volkswagnom na enem od številnih izletov po Švedskem

Marta spoprijateljila tudi z učiteljema, Erikom Berglundom ${ }^{63}$ in Carlom Gustafom Boulognerjem, ${ }^{64}$ ki sta kasneje pogosto prihajala v Ljubljano kot predavatelja na tečajih Barva in oblika. Berglund je $z$ leti postal tesen in pomemben družinski prijatelj Ivanškov in bil tudi sicer pogost gost $v$ Jugoslaviji, kot pisec člankov v reviji Arhitekt in član različnih komisij na področju pohištvene industrije.

Vzporedno z rednim delom v različnih švedskih arhitekturnih birojih sta Ivanška budno spremljala razvoj sočasne švedske arhitekture, odkrivala pa sta tudi skandinavsko naravo in kulturo nasploh. Veliko sta potovala, predvsem z lastnim volkswagnom (sl. 14), po Švedski, Danski in Norveški. Pogosto sta obiskala tudi Finsko. Julija 1955 sta bila na obisku pri Alvarju Aaltu, na njegovem domu v Munkkiniemiju v predmestju Helsinkov. ${ }^{65}$ Raziskovala sta organizacijo in metodologijo stanovanjskega raziskovanja, preučevala švedski sistem vzgoje stanovalcev k višji stanovanjski kulturi, ${ }^{66}$ o vsem tem pa poročala domov. Po naročilu Franca Drobeža, predsednika Strokovnega sveta za stanovanjska vprašanja pri Izvršnem svetu LRS, sta leta 1959 pripravila študijo Stanovanjsko raziskovanje na Švedskem. Njuno izredno zanimanje za raziskovalno delo je vzbudila doktorska disertacija švedskega arhitekta Lennarta Holma z naslovom Družina in stanovanje. ${ }^{67} \mathrm{O}$ njunih izsledkih je Ivanšek poročal tudi v reviji Arhitekt. V članku Osnovne poteze skandinavske stanovanjske politike je opisal način reševanja stanovanjskega vprašanja na Švedskem, Danskem,

63 Erik Berglund (1921-2008) je bil švedski arhitekt, oblikovalec pohištva in raziskovalec. V sodelovanju s Tryggve Johansson je ustanovil Berglund Färgskolan, barvno šolo, ki je organizirala tečaje »naravnega barvnega sistema«, ki so v petdesetih in šestdesetih potekali tako na Švedskem kot v tujini. Gl. Per BERG, Erik Berglund, Allehanda, https://www.allehanda.se/artikel/erik-berglund (12. 10. 2020).

${ }^{64}$ Carl Gustaf Boulogner (1918-2002) je bil švedski oblikovalec interierja. Gl. Boulogner, Carl Gustaf, Vem är Wem. Norrland, supplement, register (ur. Åke Davidsson), Stockholm 1968, str. 539.

65 France IVANŠEK, Srečanja z Alvarom Aaltom, Naši razgledi, 36/10, 29. 5. 1987, str. 296. Potovanje na Finsko je Ivanškoma plačala finska ambasada pod pogojem, da Ivanšek v Arhitektu objavi članek o Aaltu; gl. France IVANŠEK, Povojna dela Alvarja Aalta, Arhitekt, 7/21-22, 1957, str. 34-39.

66 IVANŠEK 1988 (op. 23), str. 9.

67 Lennart HOLM, Familj och bostad, Stockholm 1955; prim. IVANŠEK 1988 (op. 23), str. 9. 
Norveškem, Finskem in Islandiji. ${ }^{68} \mathrm{~V}$ prispevku Švedski stanovanjski standard pa je predstavil delo zadružne zveze HSB, svojega prvega delovnega mesta. ${ }^{69}$ Po vrnitvi iz Stockholma sta izdala še eno publikacijo, tokrat za Urbanistični inštitut Slovenije, z naslovom Stanovanjsko raziskovanje na Danskem (1960).

\section{Pomen švedske izkušnje}

V petdesetih letih, ko sta se Ivanška odpravila v Stockholm, je švedska stanovanjska gradnja doživljala svoj vrhunec. Združeni stanovanjsko raziskovanje, vladajoča ideologija, praktično znanje, estetske ambicije in industrijska proizvodnja so vodili k izoblikovanju visokega bivanjskega standarda. V takšnem delovnem vzdušju sta se zaposlila v različnih arhitekturnih birojih. Ivanšek je sprva delal pri HSB, kjer je spoznal pomen standardov pohištva, posameznih prostorov in odnosov med njimi. Kasneje je kot sodelavec Carla-Axla Ackinga spremljal nastajanje velike mednarodne razstave stanovanjske kulture $\mathrm{H}-55 \mathrm{v}$ Helsingborgu, na kateri je od blizu spoznal različne oblike skandinavskega prizadevanja za boljši standard bivanjskega okolja. ${ }^{70} \mathrm{~V}$ ostalih projektih se je večinoma ukvarjal s stanovanjskimi stavbami, naselji, vrstnimi hišami in stanovanjskimi bloki. Marta Ivanšek se je medtem bolj usposabljala za gledališča, v zadnjih letih pa je tudi ona sodelovala pri stanovanjskih projektih. Glede na pregledano gradivo, predvsem primarne arhivske vire, lahko sklepamo, da njuna vloga pri vseh navedenih projektih ni bila vodilna - pogosto sta bila prisotna bolj v risarski kot projektantski vlogi. $\mathrm{V}$ članku naštetih projektov tako ne moremo vključevati v njun opus, jih pa lahko razumemo kot del procesa učenja in sledenja sočasni švedski arhitekturi.

Švedska je na Ivanška naredila velik vtis. Kolege doma sta stalno obveščala o tem, s čim se srečujeta in kaj od tega bi lahko uporabili v domačih razmerah. Ivanšek je Vladimirju Bracu Mušiču v pismu 1. avgusta 1954 pisal: »Moderna arhitektura v Stockholmu, predvsem stanovanjska, je tukaj povečini zelo prepričljiva, vendar pravo nasprotje pojmovanja n.pr. Le Corbusierjeve arhitekture. Pogledi Skandinavije se v tem pač popolnoma ločijo od kontinenta, oz. ne čutijo potrebe z njim, ker so v realnosti že mnogo dalje kot kontinent v svojih načrtih.« Čez nekaj let (29. avgusta 1957, prav tako v pismu Vladimirju Bracu Mušiču) je svoje prepričanje še utrdil: »Švedi so tudi v pogledu notranje ureditve zaenkrat še nenadkriljeni, v teh stanovanjih se da res stanovati /.../ «. ${ }^{71} \mathrm{~A}$ obenem je priznaval, da na Švedskem gotovo niso bile doma genialne ideje, niti likovne niti konstruktivne, zavidanja vreden je samo arhitekturni standard, ta pa je produkt visoke civilizacije in ne kulture. ${ }^{72}$

Konec oktobra 1959 sta Ivanška po več kot štirih letih bivanja na Švedskem zapustila Stockholm in se vrnila v Ljubljano. Zanju je bila švedska izkušnja gotovo močnejša kakor za druge slovenske

68 France IVANŠEK, Osnovne poteze skandinavske stanovanjske politike, Arhitekt, 5/16, 1955, str. 36-40.

69 France IVANŠEK, Švedski stanovanjski standard, Arhitekt, 5/17, 1955, str. 11-18.

70 IVANŠEK 1988 (op. 23), str. 9. Ivanšek navaja dva švedska dogodka, ki sta bila za njegovo nadaljnjo strokovno usmeritev odločilnega pomena, poslušanje javnega zagovora doktorske disertacije z naslovom Družina in stanovanje švedskega arhitekta Lennarta Holma na KTH - Kraljevi tehniški visoki šoli v Stockholmu in delovno sodelovanje na razstavi skandinavske stanovanjske kulture H-55 v Helsingborgu.

71 Zasebni arhiv Ustanove France in Marta Ivanšek, Korespondenca, pismo Franceta Ivanška Vladimirju Bracu Mušiču, 29. 8. 1957.

72 Zasebni arhiv Ustanove France in Marta Ivanšek, Korespondenca, pismo Franceta Ivanška Vladimirju Bracu Mušiču, 13. 12. 1956. 


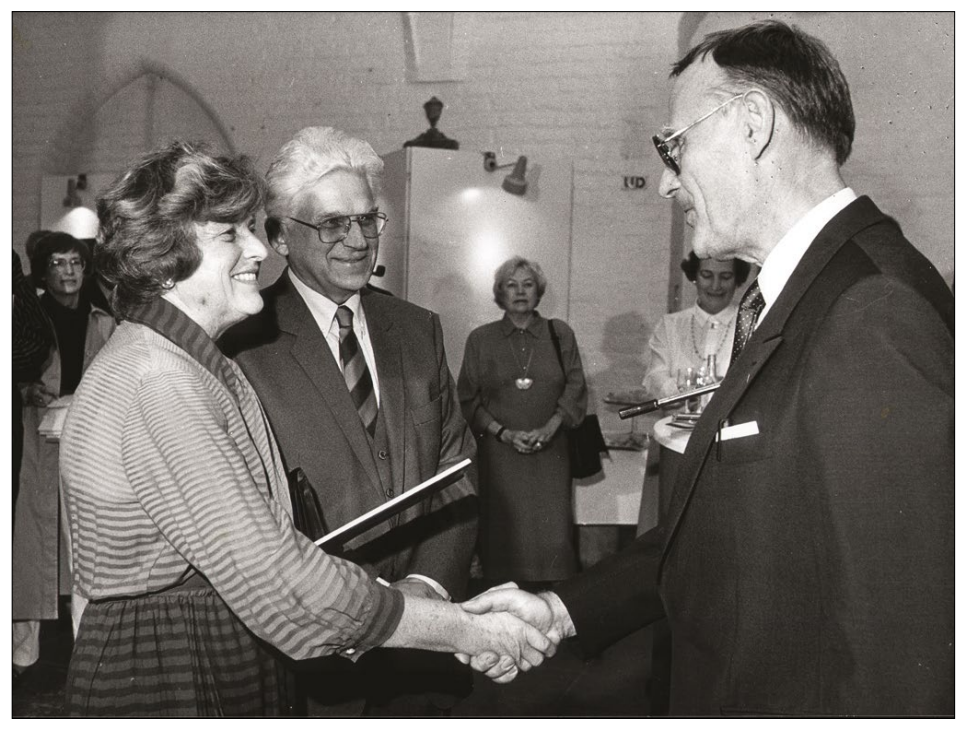

15. Marta in France Ivanšek z Ingvarjem Kampradom, ustanoviteljem in lastnikom verige trgovin IKEA, ob podelitvi nagrade za izjemne inovacije $v$ arhitekturi in oblikovanju interierja, København, 1986

arhitekte, zato sta jo tudi najizraziteje in najbolj aktivno prenesla v slovenski prostor. ${ }^{73} \mathrm{~V}$ svojem delu sta se vseskozi opirala na skandinavska izhodišča in načine dela, pa tudi na tamkajšnje zadržano načrtovanje in oblikovanje. Na osnovi švedske izkušnje sta razvila svoje zanimanje za stanovanjsko raziskovanje, razširila znanje o stanovanjski gradnji, izoblikovala tako tehnični kot likovni pristop $\mathrm{k}$ notranjemu opremljanju in razvila občutljivost za skupine ljudi s posebnimi potrebami, predvsem za starejše. Poleg tega sta prevzela tudi zadržano skandinavsko estetiko, ki je v njunih projektih ne moremo spregledati. Zaslutimo jo lahko tako pri naselju Murgle kot pri notranji opremi, na primer kuhinji SVEA, ki sta jo zasnovala leta 1961 na podlagi švedskega modela in jo tudi poimenovala po švedski pokrajini Svealand. Po vrnitvi domov Ivanška stikov s Švedsko nista prekinila. Še vedno sta se vračala k švedskim vzorcem, ob tem pa obdržala tudi neposredne zveze, prijateljske in poslovne stike, ki sta jih negovala še desetletja pozneje. Na Švedsko sta potovala in od tam uvažala opremo za trgovini Interier v Ljubljani in Ambient v Mariboru. Ostajala sta v stiku s švedskimi strokovnjaki in ustanovami. V Ljubljano sta pripeljala tudi izredno uspešne in pomembne tečaje Barva in oblika, ki sta jih organizirala štiri leta zapovrstjo (1961-1964) in k njihovi izvedbi povabila švedske predavatelje, med njimi tudi Martinega znanca iz Uddevalle Erika Berglunda. Leta 1964 sta s klubom Barva in oblika ter organizacijo proizvajalcev, oblikovalcev in potrošnikov Svenska slöjdföreningen iz Stockholma organizirala švedsko-jugoslovansko konferenco v Ljubljani. ${ }^{74}$ Vsi ti napori so privedli korak bližje k višjemu standardu bivanjskega prostora, ki je bil tekom celotnega opusa vodilo arhitektov Ivanšek. Kot dodatna vzpodbuda in hkrati priznanje za njuno izhodišče, sorodno skandinavskemu, pa je bila nagrada IKEA, ki jima jo je leta 1986 za izjemne inovacije v arhitekturi in oblikovanju interierja podelila Fundacija IKEA (sl. 15).

73 Za temeljitejšo analizo skandinavskega vpliva na delo Ivanškov in tudi na slovensko arhitekturo nasploh gl. MALEŠIČ 2013 (op. 3).

74 Program je obsegal barvo kot izrazni element v prostoru, podatke o planiranju stanovanj, organizacijo raziskav, ki so osnova stanovanjske graditve, raziskave pohištva, svetil, vzgojo arhitektov in industrijskih oblikovalcev, podatke o stanovanjskem natečaju na osnovi ankete in razmišljanja o novi mestni sliki; gl. Majda DOBRAVEC, Kultura stanovanja in njegove okolice. Zapiski o švedsko-jugoslovanski konferenci, Naši razgledi, 13/14, 25. 7. 1964, str. 281. 


\title{
Drawings from the Stockholm Archives
}

\section{An Attempt to Reconstruct the Swedish Experience of Architects France and Marta Ivanšek}

\author{
Summary
}

The influence of Scandinavian, especially Swedish, models represents an important chapter in the history of Slovene post-war architecture. The architects France and Marta Ivanšek are often considered an important part of this chapter as examples of architects on whom Swedish experience left a very strong mark, almost as 'ambassadors' of Swedish culture. From Scandinavia they brought a number of models which proved to be crucial for the improvement of housing standards, such as the idea of low-rise highdensity housing (Murgle settlement in Ljubljana), the Scandinavian system for modern kitchen design (SVEA) and the Barva in Oblika ('Colour and Form') courses on the Swedish Natural Colour System and its applicatibility in design, architecture, furniture and textile industry. Numerous researchers of post-war Slovenian architecture have briefly mentioned France and Marta Ivanšek's Swedish experience, but topic has not yet been researched or presented in detail. The article seeks to provide an insight into the years the architects Ivanšek spent in Stockholm. Based on primary sources from the Stockholm archives, the architects' own records and correspondence, it reconstructs their Swedish experience, what they saw and what kind of work they undertook while living there.

France and Marta Ivanšek travelled to Stockholm in 1954, when Swedish housing construction reached its peak. In Sweden, advancements in housing research combined with the prevailing social and ideological programme, practical knowledge, aesthetic ambitions and industrial production had contributed to the widely admired high standard of living. It was in these circumstances that France and Marta Ivanšek obtained their positions in various architectural offices. France Ivanšek started at HSB (Hyresgästernas sparkasse- och byggnadsförening) - a cooperative housing association, where he learned about the importance of standards for furniture, furnishings and surface areas of specific rooms in apartments. Later, as a collaborator of the architect Carl-Axel Acking, he remained in the field of housing, as an assistant at the international exhibition of residential culture H-55 in Hälsingborg and also with other projects where he mostly designed residential buildings, terraced houses and apartment blocks. Marta Ivanšek, meanwhile, came to specialize more in theatres while working in the office of David Helldén, but was later also involved in housing projects in the office of the architect Georg Varhelyi.

The Swedish experience left a strong mark on the Ivanšeks. In their work they always relied on ideas and ways of working developed during their years in Stockholm, as well as on the understated but elegant Scandinavian planning and design. In Sweden they developed their interest in housing research, expanded their knowledge of residential construction, developed both a technical and artistic approach to interior design and a sensitivity for groups of people with special needs, especially the elderly. They also adopted the understated Scandinavian aesthetics, which is unmistakable in their projects. It can be detected both in the Murgle development and in their interior design, such as the SVEA kitchen, which they designed in 1961 based on a Swedish model and named after the Swedish province of Svealand. When back at home, France and Marta Ivanšek still nurtured their connections to Sweden through their friends, business partners, experts and the institutions they worked for. In Ljubljana they invited Swedish experts to lecture at the extremely successful and important Colour and Form courses, which they organized for four years in a row (1961-1964). In 1964, the Svenska slöjdföreningen (The Swedish Society of Crafts and Design) from Stockholm organized a Swedish-Yugoslav conference in Ljubljana with the Colour and Form Club and a group of producers, designers and consumers from Stockholm. All these efforts contributed to a higher standard of living space design, which was a leitmotif in the Ivanšeks' work. 


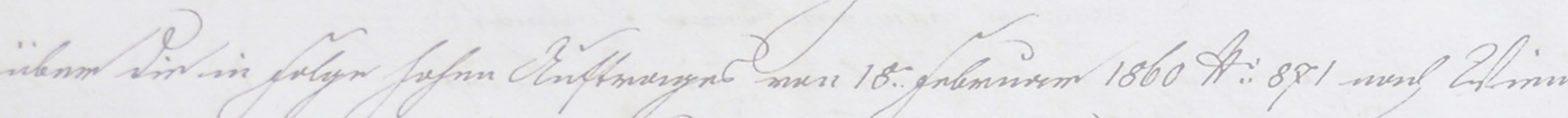

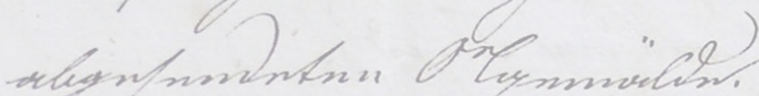

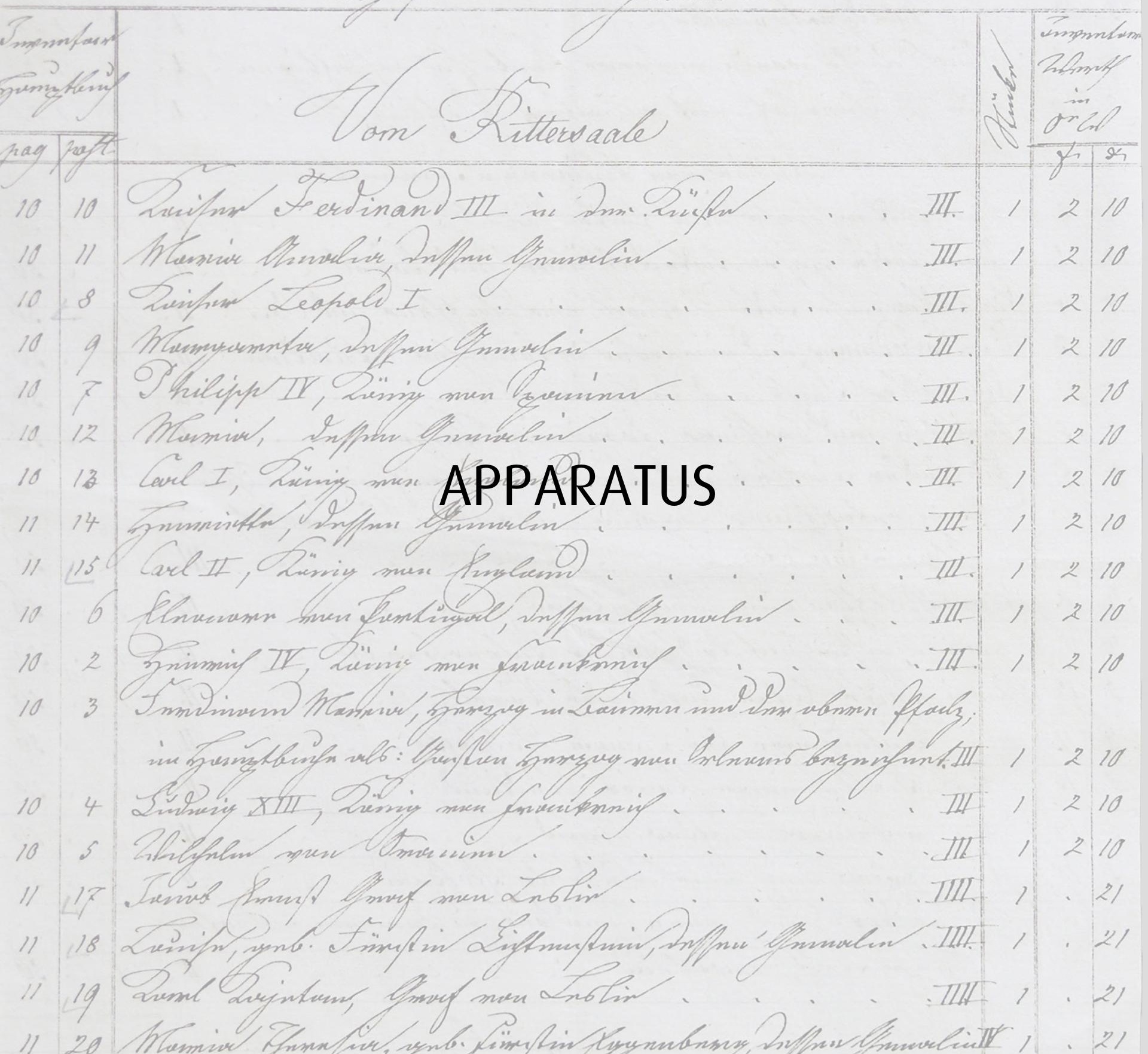

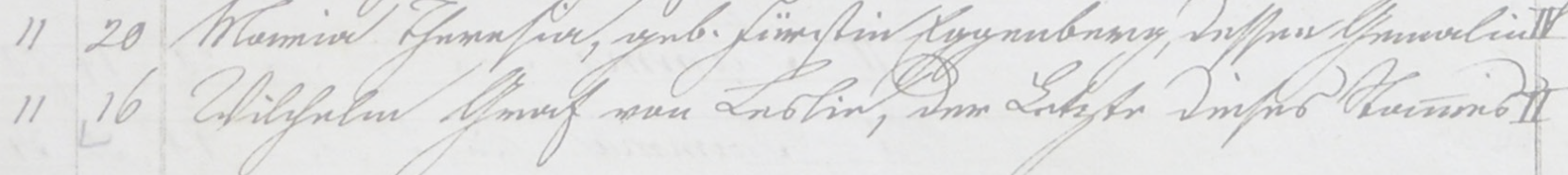




\section{IZVLEČKI IN KLJUČNE BESEDE} Abstracts AND KeYWORDS

\section{Janez Balažic \\ Fragmentarno ohranjene gotske stenske poslikave na zahodnem panonskem robu}

1.01 Izvirni znanstveni članek

Avtor v prispevku obravnava fragmentarno ohranjene stenske poslikave, pripisane regionalnim slikarskim delavnicam, ki so zarisovale t. i. navpično vplivno os po zahodnem panonskem robu. Zbrani primeri navkljub okrnjeni predstavnosti pomembno dopolnjujejo umetnostnozgodovinsko podobo umetnostne produkcije tega prostora v času Luksemburžanov. Prispevek kaže na tvorne povezave med pokrovitelji in umetnostnimi delavnicami. Njihovo produkcijo pred sredino 14. stoletja zaznamuje izzvenevanje visokogotskega linearnega stila, zatem pa ob italijanskih trečentističnih spodbudah "mešani« ali "prehodni« slog tretje in zadnje četrtine 14. stoletja, na vrhuncu češko-dunajske produkcije okoli leta 1400 pa tudi tu zmaga mednarodni gotski slog, ki odzvanja še globoko v 15. stoletje.

Ključne besede: fragmenti, gotske poslikave, zahodni panonski rob, Luksemburžani, visokogotski linearni stil, mešani slog, prehodni slog, mednarodni slog

\author{
Janez Balažic \\ Fragmentarily Preserved Gothic Murals \\ on the Western Edge of Pannonia \\ 1.01 Original scientific article
}

The author discusses the fragmentarily preserved murals attributed to regional painting workshops which exemplify the so-called vertical influence axis on the western edge of Pannonia. Despite their fragmentary condition, the examples discussed make an important contribution to our understanding of the artistic production in this territory at the time of the House of Luxembourg. The paper explores the productive connections between artistic workshops and their patrons. The artistic output of the workshops was characterized by the gradual fading of the high Gothic linear style already before the middle of the $14^{\text {th }}$ Century, and by a 'mixed' or 'transitional' style under Italian Trecento influences in the second half of the $14^{\text {th }}$ Century, whereas at the time of the peak of Czech and Viennese production around 1400 the international Gothic style prevails and is still discernible well into the $15^{\text {th }}$ Century.

Keywords: fragments, Gothic paintings, western edge of Pannonia, the House of Luxembourg, High Gothic linear style, mixed style, transitional style, international style 


\author{
Martina Malešič \\ Risbe iz stockholmskih arhivov. \\ Poskus rekonstrukcije švedske izkušnje arhitektov \\ Franceta in Marte Ivanšek
}

\title{
1.01 Izvirni znanstveni članek
}

Arhitekta France in Marta Ivanšek se v slovenski arhitekturni zgodovini pogosto omenjata kot »ambasadorja« švedske kulture, ki sta iz Skandinavije v slovenski prostor prinesla vrsto za napredek stanovanjskega standarda ključnih modelov, na primer urbanistično idejo nizko-goste stanovanjske zazidave (naselje Murgle v Ljubljani), skandinavski sistem moderne laboratorijske kuhinje (SVEA) ter tečaje Barva in oblika. Švedsko izkušnjo arhitektov Ivanšek omenjajo številni raziskovalci povojne slovenske arhitekture, vendar področje še ni bilo podrobno raziskano in predstavljeno. Prispevek prinaša vpogled $\mathrm{v}$ leta, ki sta jih Ivanška preživela $\mathrm{v}$ Stockholmu. S pomočjo primarnega gradiva iz stockholmskih arhivov, lastnih zapisov arhitektov in korespondence poskuša rekonstruirati njuno bivanje in delo v Stockholmu.

Ključne besede: France Ivanšek, Marta Ivanšek, stanovanjska gradnja, Švedska, bivanjska kultura, slovenska arhitektura

\section{Mateja Maučec \\ Vizualna propaganda Stadlerjevih ekumenskih prizade- vanj $v$ freskah Ivane Kobilce}

\subsection{Izvirni znanstveni članek}

Članek se ukvarja z likovnim prispevkom slovenske slikarke Ivane Kobilce v sarajevski semeniški cerkvi sv. Cirila in Metoda. Poslikava dela cerkve je bila med prvimi naročili, ki jih je umetnica pridobila v Sarajevu, ter po obsegu tudi njeno največje delo. Umetnica je poslikala del kupole, severni steni obeh krakov transepta in štiri tonde, dva na pevskem koru ter dva na stranskih emporah. Za freske, ki združujejo jezuitsko in ekumensko ikonografijo, je ikonografski program sestavil prvi sarajevski nadškof dr. Josip Stadler, freske pa so priča njegovih neuresničenih cerkveno-političnih ambicij po združitvi vzhodne in zahodne Cerkve.

Ključne besede: ekumenizem, Josip Stadler, stensko slikarstvo, Ivana Kobilca, vizualna propaganda, Bosna in Hercegovina

\author{
Martina Malešič \\ Drawings from the Stockholm Archives. \\ An Attempt to Reconstruct the Swedish Experience \\ of Architects France and Marta Ivanšek
}

1.01 Original scientific article

Slovene architectural history often mentions the architects France and Marta Ivanšek as 'ambassadors' of Swedish culture. From Scandinavia they brought a number of models which proved to be crucial for the improvement of housing standards such as the idea of low-rise high-density housing (e.g. the Murgle development in Ljubljana), Scandinavian modern kitchen design (SVEA) and the Barva in Oblika ('Colour and Form') courses on the Swedish Natural Colour System and its applicatibility in design, architecture and textile industry. Numerous researchers of post-war Slovenian architecture have mentioned France and Marta Ivanšek's Swedish experience, but the topic has not yet been researched or presented in detail. This article seeks to provide an insight into the years the architects spent in Stockholm. Based on primary sources from the Stockholm archives, the architects' own records and correspondence, it reconstructs their stay and work in Stockholm.

Keywords: France Ivanšek, Marta Ivanšek, housing, Sweden, dwelling culture, Slovene architecture

\author{
Mateja Maučec \\ Visual Propaganda of Stadler's Ecumenic Project \\ in Frescoes by Ivana Kobilca
}

\subsection{Original scientific article}

The article deals with the artistic contribution of the Slovene painter Ivana Kobilca in the Sarajevo seminary Church of Sts Cyril and Methodius. The painting of part of the church was among the first commissions that the artist obtained in Sarajevo, and in terms of the scope also her largest work. The artist painted part of the dome, the northern walls of the transept and four tondi, two on the organ loft and two on the side galleries. The iconographic program for the frescoes, which combine Jesuit and ecumenical iconography, was designed by the first archbishop of Sarajevo, Dr. Josip Stadler. The frescoes attest to his unrealized ecclesiastical and political ambitions of unifying the Eastern and Western Churches.

Keywords: ecumenism, Josip Stadler, wall painting, Ivana Kobilca, visual propaganda, Bosnia and Herzegovina 


\author{
Mija Oter Gorenčič \\ Redovne in umetnostne povezave med Gamingom in \\ kartuzijami $v$ današnji Sloveniji s posebnim ozirom na \\ memorio in likovno reprezentacijo Habsburžanov in \\ grofov Celjskih
}

1.01 Izvirni znanstveni članek

V članku so predstavljene redovne in umetnostne povezave kartuzij na Slovenskem s kartuzijo Gaming. Raziskava je pokazala, da je do okrog leta 1500 potekala relativno pogosta izmenjava priorjev in menihov med Gamingom in slovenskimi kartuzijami. V večini primerov je šlo za prihode menihov iz Gaminga v slovenske kartuzije, redkejši pa so bili odhodi iz slovenskih kartuzij v Gaming. Tudi umetnostnozgodovinska primerjalna in slogovna analiza sta razkrili več doslej še neopaženih povezav. Povezavo razkrivajo tudi posamezni ujemajoči se kamnoseški znaki. V slovenskih kartuzijah izstopa umetnostno naročništvo grofov Celjskih. Ti bi se pri likovni reprezentaciji lahko zgledovali prav po načinih, ki so se jih z namenom memorie v Gamingu posluževali Habsburžani.

Ključne besede: kartuzijani, kartuzijanska arhitektura, srednji vek, grofje Celjski, Habsburžani, Gaming, Žiče, Jurklošer, Bistra, Pleterje, memoria, likovna reprezentacija

\section{Vaidas Petrulis \\ Kaunas - baltsko vrtno mesto?}

\subsection{Izvirni znanstveni članek}

Med letoma 1919 in 1939, ko je imel Kaunas status začasne prestolnice Litve, sta krojila arhitekturni značaj njegovega urbanega okolja procesa, ključna za tisti čas modernizacija in napredek. V dvajsetih letih 20. stoletja je v hitro rastoči prestolnici vladalo veliko pomanjkanje stanovanj, zato so bile stanovanjske stavbe pomemben del gradbene dejavnosti in mestnega programa modernizacije skozi celotno medvojno obdobje. Med dokumente, ki so vplivali na koncept bivalnega okolja, spada urbanistični načrt za Kaunas, ki sta ga leta 1923 zasnovala danski inženir in urbanist Marius Frandsen in litovski arhitekt Antanas Jokimas. Projekt je predvidel razdelitev mesta na različne funkcionalne cone. Eno teh območij - rezidenčni Žaliakalnis - priča, da so bile med najpomembnejšimi urbanističnimi pobudami v ozadju projekta eksperimentalne zamisli Ebenezerja Howarda o vrtnem mestu. Članek s pomočjo zgodovinskih virov

\section{Mija Oter Gorenčič}

Monastic and Artistic Connections between Gaming and the Charterhouses in Present-Day Slovenia with Particular Regard to Memoria and the Visual

Representation of the Habsburgs and the Counts of Cilli

\subsection{Original scientific article}

The article presents the monastic and artistic connections between the charterhouses in Slovenia and the Gaming Charterhouse. The research shows that until around 1500 there was a relatively frequent exchange of priors and monks between Gaming and Slovenian charterhouses. In most cases these exchanges related to monks from Gaming coming to Slovenian charterhouses, while departures from Slovenian charterhouses to Gaming were considerably less frequent. Comparative and stylistic art historical analyses reveal several previously unnoticed connections. The matching mason's marks also attest to this connection. The artistic patronage of the Counts of Cilli stands out in the Slovenian charterhouses. In the visual representation they could have imitated the artistic ways used by the Habsburgs for their memoria in Gaming.

Keywords: Carthusians, Carthusian architecture, Middle Ages, Counts of Cilli, House of Habsburg, Gaming, Seitz, Gairach, Freudenthal, Pletriach, memoria, visual representation

\section{Vaidas Petrulis \\ Kaunas - a Baltic Garden City?}

\subsection{Original scientific article}

From 1919 to 1939, when Kaunas assumed the status of the provisional capital of Lithuania, the architectural character of its urban environment was forged by the processes that were characteristic of that period - modernization and progress. In the 1920s housing was in severely short supply in the rapidly growing capital, so residential buildings were a significant part of construction activity and of the city's modernization programme throughout the interwar period. Among the documents influencing the concept of living environment was a new master plan for Kaunas developed in 1923 by Danish engineer and urban planner Marius Frandsen and Lithuanian architect Antanas Jokimas. The project proposed dividing the city into different functional zones. One of these areas, residential Žaliakalnis, testifies to the fact that the experimental thoughts of Ebenezer Howard's garden city were among the most important 
preučuje, kako so Litovci poskušali posvojiti to idejo. S primerjavo teoretičnih prizadevanj in praktičnih aplikacij eksperimenta vrtnega mesta članek dokazuje, da spada Kaunas med mesta, v katerih je univerzalni koncept zelenih predmestij našel plodna tla.

Ključne besede: vrtno mesto, zeleno predmestje, modernizem, medvojna Evropa, Litva

\author{
Damjan Prelovšek \\ Plečnikovi načrti za cerkev sv. Križa v Zagrebu
}

\subsection{Izvirni znanstveni članek}

Arhitekt Jože Plečnik je za zagrebške frančiškane iz province sv. Cirila in Metoda naredil več predlogov cerkve sv. Križa s samostanom, ki naj bi postala središče nove župnije istega imena. Prvotni prostor je bil Trg kralja Petra Krešimirja. Ker pa regulacija tega dela mesta še ni bila določena, je moral svoje načrte spremeniti. Gradnjo je preprečil začetek druge svetovne vojne, po njej pa je Plečnik svoj projekt dolge in ozke cerkve (1939) zamenjal s centralno stavbo (1946-1947), ki povzema zamisli njegove neuresničene sarajevske katedrale sv. Jožefa in sočasnega načrtovanja stavbe slovenskega parlamenta. Intenzivno ukvarjanje s tem naročilom označuje širok razpon tipoloških in ustvarjalnih možnosti.

Ključne besede: Jože Plečnik, Dioniz Andrašec, zagrebški frančiškani, župnija sv. Križa, sakralna arhitektura, jezuitski samostan v Osijeku, slovenski parlament

\author{
Alessandro Quinzi \\ Rodbinske ambicije Sigismunda grofa \\ Attems Petzenstein v luči umetnostnih naročil \\ 1.01 Izvirni znanstveni članek
}

Sigismund grof Attems Petzenstein (1708-1758) je sredi 18. stoletja svojo rodbino "povzdignil do take veličine, kakršne ni dosegla v vseh preteklih časih« (G. Guelmi, urban inspirations behind it. Through the lens of the historical sources, the article examines how Lithuanians attempted to adopt this idea. Comparing the theoretical aspirations and the practical applications of the garden city experiment, the article argues that Kaunas is among the cities where the universal concept of green suburbs found fertile ground.

Keywords: garden city, green suburbs, modernism, interwar Europe, Lithuania

\section{Damjan Prelovšek}

Plečnik's Plans for the Church of the Holy Cross in Zagreb

\subsection{Original scientific article}

Architect Jože Plečnik prepared several proposals for the church of the Holy Cross and the monastery for the Zagreb Franciscans from the province of Sts Cyril and Methodius, which was to become the centre of the new parish with the same name. The original location for the project was the Square of King Peter Krešimir. However, since the traffic regulation for this part of town had not yet been determined, he had to change his plans. The construction was prevented by the start of World War II, and after it, Plečnik replaced his design for a long and narrow church (1939) with a central building (19461947), which summarises his ideas for the unrealized cathedral of St Joseph in Sarajevo and the concurrent work on the National Assembly Building of Slovenia. The intensive work on this commission is characterized by a wide range of typological and creative possibilities.

Keywords: architect Jože Plečnik, Dioniz Andrašec, the Zagreb Franciscans, parish of the Holy Cross, religious architecture, Jesuit monastery in Osijek, National Assembly Building of Slovenia

\author{
Alessandro Quinzi \\ The Family Ambitions of Sigismund Attems \\ Petzenstein in the Light of his Art Commissions \\ 1.01 Original scientific article
}

In the mid- $18^{\text {th }}$ Century Count Sigismund Attems Petzenstein (1708-1758) "raised his family to such greatness as it had not attained in all past times" (G. Guelmi, Storia 
Storia genealogico-cronologica degli Attems austriaci, 1783). Na novo pridobljeni ugled je pospremil s postavitvijo mestne rezidence na Kornu (1745) in vile v Podgori (1747-1748) ter $\mathrm{z}$ obnovo dvorca na Jazbinah (1747). Leta 1750 , ob imenovanju brata Karla Mihaela (1711-1774) za prvega goriškega nadškofa, pa je dal modernizirati pročelje mestne palače. $\mathrm{Za}$ gradbene podvige je Sigismund praviloma zaposlil arhitekta Saveria Giannija, kar dokazujejo prvič objavljeni podatki iz zapuščinskega inventarja. Slikarsko opremo je naročal pri goriških slikarjih (Johann Michael Lichtenreit, Antonio Paroli), le za oltarno sliko družinske kapele v nekdanji cerkvi sv. Frančiška se je obrnil na veronskega umetnika Giambettina Cignarolija. Čeprav Sigismund ni dočakal namestitve slike, se je ravno s tem umetniškim podvigom vpisal v elitni krog evropskih naročnikov Cignarolijevih del.

Ključne besede: Sigismund Attems Petzenstein, Karel Mihael Attems Petzenstein, Saverio Gianni, Giambettino Cignaroli, Gorica, baročna umetnost, arhitektura, 18. stoletje

\section{Samo Štefanac \\ Ponovno o koprski Pietà}

1.01 Izvirni znanstveni članek

Leseni kip Pietà v koprski stolnici, ki je bil leta 2016 v vandalskem napadu poškodovan, je bil podrobneje obravnavan že leta 2005 in pogojno označen kot beneško delo iz sredine 15 . stoletja pod vplivom muranske slikarske šole. Novejše odkritje kaže, da gre po vsej verjetnosti za padovansko delo, prav tako iz sredine 15 . stoletja. Doslej namreč ni bil opažen približno sočasni kip Pietà v Piove di Sacco, ki je nedvomno delo iste roke kot koprski in ga lahko povežemo s slikarstvom Squarcionejevega kroga.

Ključne besede: Pietà, kiparstvo 15. stoletja, Koper/Capodistria, Piove di Sacco, Padova genealogico-cronologica degli Attems austriaci, 1783). He cemented the newly acquired reputation with the erection of a town residence in Corno Square (1745), a villa in Podgora (Piedimonte, 1747-1748) and the renovation of the mansion at Jazbine (Giasbana, 1747), all in Gorizia. In 1750, when his brother Karl Michael (1711-1774) was appointed the first archbishop of Gorizia, he had the façade of the town palace modernized. As a rule, Sigismund used the architect Saverio Gianni to execute the works, as is evidenced by data from the estate inventory now published for the first time. He commissioned paintings from the Gorizian painters Johann Michael Lichtenreit and Antonio Paroli, whereas for the altar painting of the family chapel in the former church of St Francis he turned to the Veronese artist Giambettino Cignaroli. Although Sigismund did not live to see the painting hung, it was by means of this artistic commission that he joined the elite circle of Cignaroli's European clients.

Keywords: Sigismund Attems Petzenstein, Karl Michael Attems Petzenstein, Saverio Gianni, Giambettino Cignaroli, Gorizia, Baroque art, architecture, $18^{\text {th }}$ Century

\section{Samo Štefanac \\ The Koper Pietà Revisited \\ 1.01 Original scientific article}

The wooden Pietà sculpture in the Koper Cathedral, which was damaged in a vandal attack in 2016, was studied in considerable detail in 2005 and was provisionally labelled as a Venetian work from the middle of the $15^{\text {th }}$ Century influenced by the Murano painting school. The latest findings show that the work most probably originates from Padua, also from the middle of the century. The roughly contemporary sculpture of Pietà in Piove di Sacco, which was undoubtedly made by the same sculptor as the Pietà in Koper and can be related to the painting of the circle of Francesco Squarcione, had not been noticed until now.

Keywords: Pietà, $15^{\text {th }}$ Century sculpture, Koper/Capodistria, Piove di Sacco, Padua 


\section{Polona Vidmar}

Prednik ali kralj? Recepcija portretov iz 17. stoletja

$v$ času Franca Jožefa kneza Dietrichsteina (1767-1854)

\subsection{Izvirni znanstveni članek}

Prispevek osvetljuje zanimanje Franca Jožefa kneza Dietrichsteina za zgodovino njegove rodbine, ki se je med drugim odrazilo v nakupu izvornega rodbinskega sedeža Dietrichstein na Koroškem leta 1838. Na podlagi še neobjavljene knezove korespondence $\mathrm{z}$ uradniki gospostev Dietrichstein in Gornji Ptuj, ki ju je rodbina podedovala po grofih Lesliejih, je analizirano njegovo iskanje sledi za predniki na Koroškem in Štajerskem, prikazani pa so tudi nakupi predmetov. Predstavljene so knezove težnje, da bi s podedovanimi, kupljenimi in naročenimi portreti poudaril pomen svoje rodbine in prednikov. Kot vzorčni primer recepcije portretov je izbrana serija štirinajstih portretov evropskih vladarjev, ki jo je Jakob grof Leslie v letih od 1669 do 1673 naročil za opremo dvorane ptujskega gradu. V inventarjih gradu Gornji Ptuj so od leta 1835 sedem portretirancev in portretirank kljub nedvoumnim rekvizitom, kot so krone, vladarska jabolka in žezla ter kronanjski plašči, prepoznavali kot člane in članice rodbine Leslie. Upodobljence je ustrezneje identificiral direktor knežje galerije Franz Kutschera leta 1857, tik preden so jih leta 1860 odpeljali na Dunaj in od tam v grad Frýdlant na Češkem. Prispevek osvetljuje tudi pomen knežjih uradnikov, zlasti Moritza Seehanna in Ferdinanda Raispa, za razcvet zanimanja za zgodovino in umetnostne spomenike na Ptuju v 19. stoletju.

Ključne besede: portret, baročno slikarstvo, naročništvo, transfer umetnin, ptujski grad, Franc Jožef knez Dietrichstein, Jakob grof Leslie, Ferdinand Raisp

\section{Polona Vidmar}

Ancestor or King? The Reception of $17^{\text {th }}$ Century

Portraits in the Time of Franz Joseph,

Prince of Dietrichstein (1767-1854)

\subsection{Original scientific article}

The article seeks to shed light on Franz Joseph, Prince of Dietrichstein's interest in the history of his own family, which was reflected among other things in his purchase of the original Dietrichstein family seat in Carinthia in 1838. Franz Joseph's search for the traces of his ancestors in Carinthia and Styria as well as his purchases of objects are analysed based on the prince's not yet published correspondence with the clerks of the seigneuries of Dietrichstein and Gornji Ptuj, which his family inherited from the Counts of Leslie. The article discusses the prince's aspirations to use the inherited, purchased, and commissioned portraits to emphasise the significance of his family and ancestors. As a representative example of the reception of portraits, a series of 14 portraits of European rulers, which Jakob Count of Leslie commissioned for the furnishing of the hall of Ptuj castle between 1669 and 1673 was chosen. Since 1835, seven of the 'sitters' had been recognized in the inventories of the Gornji Ptuj castle as members of the Leslie family, despite the presence of unambiguous props in the paintings, such as crowns, royal orbs and sceptres, and coronation cloaks. The individuals depicted were more accurately identified by the director of the princely gallery Franz Kutschera in 1857, shortly before they were taken to Vienna in 1860 , and from there to Frýdlant castle in Bohemia. The paper also highlights the significance of the princely clerks, especially Moritz Seehann and Ferdinand Raisp, for the burgeoning interest in historical and artistic monuments in Ptuj in the $19^{\text {th }}$ century.

Keywords: portrait, Baroque painting, patronage, transfer of artworks, Ptuj castle, Franz Joseph Prince of Dietrichstein, Jakob Count of Leslie, Ferdinand Raisp 


\section{SodelaVcI}

\section{CONTRIBUTORS}

Doc. dr. Janez Balažic

Univerza v Mariboru, Pedagoška fakulteta

Oddelek za likovno umetnost

Koroška cesta 160

SI-2000 Maribor

janez.balazic@um.si

Asist. dr. Martina Malešič

Univerza v Ljubljani, Filozofska fakulteta

Oddelek za umetnostno zgodovino

Aškerčeva 2

SI-1000 Ljubljana

martina.malesic@ff.uni-lj.si

Mateja Maučec

Bratov Učakar 118

SI-1000 Ljubljana

mateja.maucec@gmail.com

Doc. dr. Mija Oter Gorenčič

ZRC SAZU, Umetnostnozgodovinski inštitut

Franceta Steleta

Novi $\operatorname{trg} 2$

SI-1000 Ljubljana

mija.oter@zrc-sazu.si

Dr. Vaidas Petrulis

Kauno technologijos universitetas, Architektūros

ir statybos institutas

Architektūros ir urbanistikos tyrimų centras

Tunelio gatvè 60

LT-44405 Kaunas

Lietuva

vaidas.petrulis@ktu.lt
Dr. Damjan Prelovšek

Zarnikova ulica 11

SI-1000 Ljubljana

damjan.prelovsek@zrc-sazu.si

Alessandro Quinzi
Musei Provinciali di Gorizia
Borgo Castello 13
IT-34170 Gorica
alessandro.quinzi@provincia.gorizia.it

Red. prof. dr. Samo Štefanac

Univerza v Ljubljani, Filozofska fakulteta

Oddelek za umetnostno zgodovino

Aškerčeva 2

SI-1000 Ljubljana

samo.stefanac@ff.uni-lj.si

Izr. prof. dr. Polona Vidmar

Univerza v Maribori, Filozofska fakulteta

Koroška cesta 160

SI-2000 Maribor

polona.vidmar@um.si 


\section{VIRI ILUSTRACIJ \\ Photographic Credits}

Janez Balažic

1-2, 6-15, I-VI: Janez Balažic.

3: (C) Nagyboldogasszony (Bencés) Templom, Šopron.

4-5 : ( O Országos Müelmlékvédelmi Hivatal, Budimpešta.

\section{Martina Malešič}

1-2, 6-7, 9, 11, 14-15: (C) Ustanova France in Marta Ivanšek, Ljubljana.

3-5, 8, 10, 12-13: (C) Svenskt arkitektur- och designcentrum ArkDes, Stockholm.

\section{Mateja Maučec}

1: Arhiv Republike Slovenije, Ljubljana.

2-6: Mateja Maučec.

7-8: D. Damjanović, Umjetnićko blago Strossmayerove katedrale u Đakovu, Đakovo 2017.

\section{Mija Oter Gorenčič}

1: (C) INDOK center, Direktorat za kulturno dediščino, Ministrstvo za kulturo Republike Slovenije, Ljubljana (risala: Zvonimir Juretin 1971 (zgoraj), A. Koštomaj 1964 (spodaj)).

2-4, 8: (C ZRC SAZU, Umetnostnozgodovinski inštitut Franceta Steleta, Ljubljana (foto: Mija Oter Gorenčič).

5, 9: (C) ZRC SAZU, Umetnostnozgodovinski inštitut Franceta Steleta, Ljubljana (risal: Nejc Bernik). 6: Maisons de l'Ordre des Chartreux. Vues et notices, 4, Parkminster 1919.

7: (C) ZRC SAZU, Umetnostnozgodovinski inštitut Franceta Steleta, Ljubljana (foto: Andrej Furlan). 10-13: (C) ZRC SAZU, Umetnostnozgodovinski inštitut Franceta Steleta, Ljubljana (foto: Gorazd Bence). 14: osebni arhiv avtorice.

\section{Vaidas Petrulis}

1, 13: (C) Kauno regioninis valstybės archyvas, Kaunas.

2: Personal collection of Antanas Burkus.

3-4: Kauno miesto statistikos metraštis, 1, Kaunas 1939.

5, 9-11: (C) Lietuvos centrinis valstybės archyvas, Vilnius.

6: (c) Lietuvos nacionalinis muziejus, Vilnius.

7: Statybos menas ir technika, 1/2-3, 1922.

8: Vaidas Petrulis.

12: Edward Denison.

14-15: (C Šiaulių „Aušros“ muziejus, Šilauliai (foto: Vincas Uždavinys).

\section{Damjan Prelovšek}

1: F. Stele, A. Trstenjak, J. Plečnik, Architectura perennis, Ljubljana 1941.

2 -5, 7-13: (C) Muzej in galerije mesta Ljubljana.

6: (C) Arhiv province sv. Cirila in Metoda, Zagreb (foto: Damjan Prelovšek). 


\section{Alessandro Quinzi}

1: (C) Narodna galerija, Ljubljana.

2-7: (C) Musei Provinciali di Gorizia, Gorica (foto: Carlo Sclauzero).

\section{Samo Štefanac}

1, 4-6, 12, 14: Samo Štefanac.

2: Dioecesis Iustinopolitana. Spomeniki gotske umetnosti na območju koprske škofije, Koper 2000.

3: Matej Klemenčič.

7-11, 13: () Diocesi di Padova.

\section{Polona Vidmar}

1, 3-4: ( ) Moravský zemský archiv v Brně, Brno (foto: Polona Vidmar).

2, 6, 8: ( Knjižnica Ivana Potrča, Ptuj.

5: Barbara Žabota.

7: (C) Státní oblastní archiv v Zámrsku, Zámrsk (foto: Polona Vidmar).

9: (C) Pokrajinski muzej Ptuj - Ormož, Ptuj, fototeka.

10: () Zgodovinski arhiv Ptuj (foto: Branko Vnuk).

11-13, 15-18: (C) Státní hrad a zámek Frýdlant, Frýdlant.

14: Vnderschidliche geistliche vnd weltliche, weibliche, vnd mannliche Contrafait /.../, Ljubljana-Zagreb 2008.

19: (C) Státní hrad a zámek Frýdlant, Frýdlant (foto: Polona Vidmar). 


\section{(C) 2021, avtorji in ZRC SAZU}

Besedilo tega dela je na voljo pod pogoji slovenske licence Creative Commons 4.0 CC BY NC ND, ki pa ne velja za slikovno gradivo. Za kakršnokoli nadaljnjo rabo slikovnega gradiva je treba pridobiti dovoljenje imetnika avtorskih pravic, navedenega $\mathrm{v}$ poglavju Viri ilustracij. Za avtorske pravice reprodukcij odgovarjajo avtorji objavljenih prispevkov.

\section{(C) 2021, Authors and ZRC SAZU}

The text of this publication is available under the conditions of the Slovenian licence Creative Commons 4.0 CC BY NC ND, which is not valid for the published images. Any further use of images requires permission from the copyright holder, stated in the section Photographic Credits. The copyrights for reproductions are the responsibility of the authors of published papers. 
ACTA HISTORIAE ARTIS SLOVENICA 26|1 • 2021

\section{Vsebina $\cdot$ Contents}

Janez Balažic, Fragmentarno ohranjene gotske stenske poslikave na zahodnem panonskem robu • Fragmentarily Preserved Gothic Murals on the Western Edge of Pannonia

Mija Oter Gorenčič, Die monastischen und kunsthistorischen Beziehungen zwischen Gaming und den Kartausen im heutigen Slowenien unter besonderer Berücksichtigung der Memoria und der Herrschaftsrepräsentation der Habsburger und der Grafen von Cilli • Redovne in umetnostne povezave med Gamingom in kartuzijami v današnji Sloveniji s posebnim ozirom na memorio in likovno reprezentacijo Habsburžanov in grofov Celjskih

Samo Štefanac, Ponovno o koprski Pietà • Di nuovo sulla Pietà di Capodistria

Alessandro Quinzi, Rodbinske ambicije Sigismunda grofa Attems Petzenstein v luči umetnostnih naročil •

Le ambizioni familiari del conte Sigismondo Attems Petzenstein alla luce delle committenze artistiche

Polona Vidmar, Vorfahr oder König? Zur Rezeption der Porträts des 17. Jahrhunderts unter Franz Josef Fürst Dietrichstein (1767-1854) • Prednik ali kralj? Recepcija portretov iz 17. stoletja v času Franca Jožefa kneza Dietrichsteina (1767-1854)

Mateja Maučec, Vizualna propaganda Stadlerjevih ekumenskih prizadevanj v freskah Ivane Kobilce • visual Propaganda of Stadler's Ecumenic Project in Frescoes by Ivana Kobilca

Vaidas Petrulis, Kaunas - a Baltic Garden City? • Kaunas - baltsko vrtno mesto?

Damjan Prelovšek, Plečnikovi načrti za cerkev sv. Križa v Zagrebu • Plečnik's Plans for the Church of the Holy Cross in Zagreb

Martina Malešič, Risbe iz stockholmskih arhivov. Poskus rekonstrukcije švedske izkušnje arhitektov Franceta in Marte Ivanšek - Drawings from the Stockholm Archives. An Attempt to Reconstruct the Swedish Experience of Architects France and Marta Ivanšek

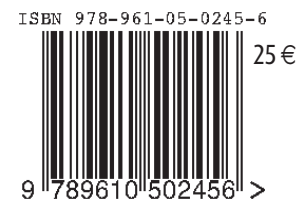

